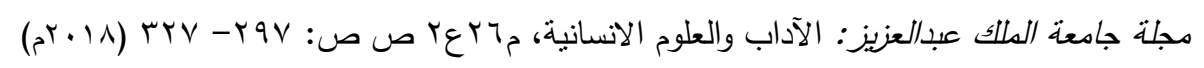

DOI:10.4197 / Art.26-2.13

التاريخ الثفوي لمدينة جدة في القرنين التاسع عشر والعشرين:

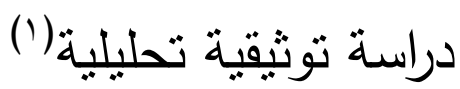

د. حسنة الغامدي ( جامعة الملك عبد العزيز)

د. طارق العجال (جامعة عفت)

مستخلص يعدّ التاريخ الثفوي للمدن والمجتمعات أحد أهم روافد الكتابة التاريخية للنطورات السياسية والاقتصادية والتقافية، وجملة التحولات الاجتماعية التي تعتري المجتمعات، ونظراً لكون مدينة جدة إحدى أهم المدن في العالم الإسلامي بحكم موقعها الجغرافي ودورها الاقتصادي، ودورها كمدخل لمدينة مكة المكرمة عاصمة قلوب المسلمين

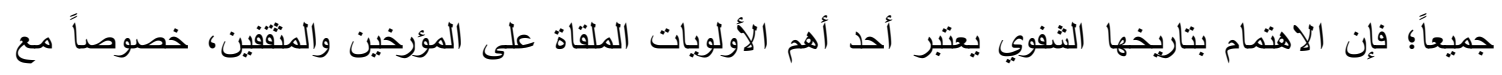
النقص الواضح في التاريخ المكتوب لهذه المدينة التاريخية، وبقاء العديد من الثغرات الزمنية في حاجة ماسة للبحث التهات والتقصي، تحاول هذه الدراسة استقصاء كل جهود جمع وتقصي ناريخ جدة الثفوي، وتقيمم جميع المحاولات التي تمت، وتطرح الدراسة أبعادًا لبحوث وموضوعات من شأنها أن تطرح في المستقبل، وقد اعتمدت الدراسة المنهج الاستقصائي التحليلي لحصر ودراسة وتحليل كافة الأعمال المنشورة. وقد وصلت الدراسة لجملة من النتائج والتقييمات التي من شأنها أن تساهم في خدمة الباحثين والمؤرخين المهنمين بتوثيق وتأريخ أحداث وتفاعلات الأيام والثقافة في مدينة جدة. الكلمات المفتاحية: جدة، التاريخ الثفوي، الحارات، التراث الثعبي، التاريخ المكتوب، السعودية. 
العامة في المدينة، فلا يكاد أسبوع ينقضي إلا تقام ندوة هنا أو مؤتمر هنا، أو حفلة توقيع كتاب لجدّواي يعبر عن عشقه لمدينته بين صفحات كتاب جديد. إن هذا الاهتمام المتزايد بتوثيق تناربخ جدة وسد الثغرات التوثيقية في تاريخها ينبئ عن وعي عميق بات راسخاً في عقول مثقفي المدينة وأبنائها من أنه يجب ربط تطور المدينة وحداثتها المتسارعة بماضيها العربق حفظاً لكيونونتها من الضياع والاندثار، كما يلفت انتباهنا إلى وجوب دعم هذه الجهود برافد وثثق في الكتابة التاريخية، وهو المصادر الثفوية أو التاريخ المحكي الذي لا زال يتذاوله كبار المدينة ومعمريها عن عموم الأحداث وتفاصليها، التي ساهمت في صناعة الحاضر الذي نعيشه الآن، هذه المصادر الثفوية التي قطعت المملكة العربية السعودية في جمعها وتوثيقها شوطاً لا تقارن به في ضخامته وإتقانه بجهود الكثير من الدول العربية مجتمعة، بل تقارن فيه بجهود دول غربية مثل بريطانيا، والولايات المتحدة الأمريكية التي كان لها شرف إدخال المصادر الثفوية إلى حيز الاعتراف التاريخي. ونظراً لأهمية المصادر الشفوية في إتمام رسم تفاصيل الأحداث التي أسست لحياة مدينة جدة السياسية والثقافية والاجتماعية والعمرانية، ودورها في سد ثخرات التاريخ التي أغفلتها الوثيقة التاريخية أو كتب التاريخ المعروفة؛ فقد عقدنا العزم على أن أن نُسهم بجهدنا في جهود إتمام رسم تقاصيل تاريخ هذه

\section{المقدمة}

تعدّ مدينة جدة أحد أهم المدن وأكثرها شهرة في العالم وفي العالم الإسلامي بشكل خاص، نظراً لمكانتها الجغرافية والاقتصادية، ونظراً لارتباطها الوثيق بمكة المكرمة التي تعدّ مدينة جدة متتفسها وبوابتها الأشهر في العالم، لذا احتلت جدة موطئًاً في كافة كتب الرحالة والمؤرخين المسلمين وغير المسلمين، الذين جلبه الحنين إلى المثناعر المقدة، أو جلبتهم السياسة ودهاليزها إلى هذه الأرجاء، وصار الحديث عن جدة ركناً ركيزاً في أغلبها، لكن وقوع جدة التاريخية تحت ظل مدينة مكة حرم هذه المدينة العربقة من حظها التوثيقي والتأربخي، الذي حظيت به المدن الكبرى من نظيراتها كالقاهرة، ودمشق، والاسكندرية، وسمرقند، و فاس، وغيرها من المدن المركزبة في مسيرة التحضر الإسلامي، وبذلك تأخر تخصيص المدينة بما بليق بمقامها من كتب وتآليف إلى مرحلة متأخرة جداً مقارنة بغيرها. ولعل تزابد وتيرة الاهتمام بتاربخ جدة العريقة في العقود الثناثة الأخيرة هو محاولة ذاتية من أبناء المدينة لاستدراك ما فات غيرهم من تأربخ، وتوثيق للأحداث التي شهدتها المدينة، فالمتأمل في كمّ المنشور والمكتوب، وحتى الفعاليات التي باتت ثقام في جدة من طرف أمانة المدينة والنوادي الأدبية الكثيرة التي تأسست حديثاً. فالمتأمل يلحظ الزخم الذي بات ناريخ المدينة يحدثه في الحياة الثقافية 
والثقافي، فالتاربخ الثفوي بمفهومه العام كما تعرفه القواميس هو "مجموعة التقالبد من أساطير ووقائع ومعارف ومذاهب وآراء وعادات وممارساتش(؟) أو : 》انتقال غير مادي للمذاهب والممارسات الدينية والأخلاقية المتوارثة من عصر إلى آخر بواسطة الكلمة المنطوقة"(). وهو بمفهومه الخاص والمقصود

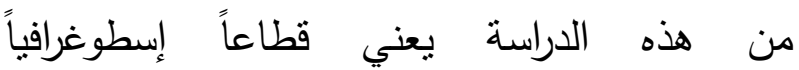
انثروبولوجياً، ومنهجاً للبحث وظيفته دراسة الماضي من خلال ذاكرة منطوقة قوامها روايات الأفراد واستحضاراتهم عن حياتهم وخبراتهم ومشاهداتهم، ولا سيما تلك التي شاركوا فيها أو كانوا مجرد شهود عيان عليها. وتحمل هذه الروايات والاستحضارات نزتيباً كرونولوجياً، وغالباً مان ملئية بالتأويلات(๕). من هذا المنطلق ولدت أهمية الحفاظ على التاريخ الثفوي والمسارعة في تدوبيه وتوثيقه نظراً لدوره في إبراز الخصوصية التقافية التي تحفظ وجود وتفرّد الثعوب والمجتمعات، وبالتالي المساهمة في بناء منهجية تتموية منكاملة ومتناسقة مع الخصوصية الثقافية.(0) وهو الأمر الذي فطنت له اليونسكو سنة ع^91، ودفعها لإعلان خطتها

(2) Charlton, Thomas L. / Myers, Lois E. and Sharpless, Rebecca (2006). (ed.), Handbook of Oral History, Lanham (MD), Altamira Press, p 14.

${ }^{(3)}$ Sheftel, Anna and Zembrzycki, Stacey, (2013).Oral history off the record: toward an ethnography of practice, New York, Palgrave Macmillan, p 33.

تليسير

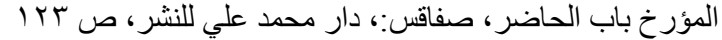

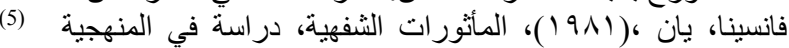

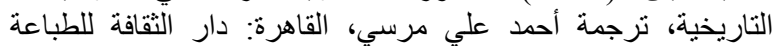

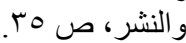

المدينة، التي منحتتا ولا زالت تمنحنا الكثير، من خلال محاولة توثيق كافة الأعمال التي كتبت عن تاربخ جدة في القرنين التاسع عشر والعشرين وتحليلها وتقييمها، والإجابة عن الأسئلة التالية: إلى أي مدى اعتمدت هذه الكتابات على المصادر الثفوية في توثيق تفاصيل الأحداث في المدينة، وهل يمكن اعتبارها مساهمات جادة في التاربخ الثفوي؟، ثم إلي أي مدى قاربت هذه الكتابات المنهجية التاريخية العلمية في توثيق الروايات الثفوية؟. من خلال الإجابة عن هذه الأسئلة تتضح الأهمية التي بتضمنها هذا الموضوع، من جهة الحاجة إلى توفّر دراسات توثثقية بيليوغرافية تحليلية نقدية عن ما كتب وما يجب المؤرخين كتابته عن تاريخ جدة، وهي حاجة درج المؤرخون والعلماء على الاعتتاء بها في تاربخ المدن والشعوب، نظراً للحاجة إلى رسم خارطة لما كُتب وما لم يُكتب، ومنهجية ونوعية ما كُتب، ومدى وفائه بالأغراض التي كتب من أجلها. وليس هناك في ظننا مدينة أولى من جدة بهذا النوع من العمل الذي تحتاج منه المدينة ربط حاضرها بماضيها، وحداثتها بعراقتها، وجمالها الحاضر بدفء أيامها الحلوة. ا - التاريخ الشفوي كمنهج تأريخي: تكمن أهمية التاريخ الثفوي للأمم والمجتمعات في القيمة الخبرية والمادية التي تحتويها مصادره سواءً أكانت المرويات الثفوية، أو مجموعة العادات والتقاليد التي تخنزل قروناً من التطور الاجتماعي 
التنوين في التاريخ الإسلامي، الذي نأخر كثيرا عن انطلاق الدولة الإنسلامية، واستمر الحال على ما هو الإدي عليه من اعتماد المؤرخين على التاريخ الدكتوب الإني والتاريخ الثفوي إلى تاريخ متأخر جدا مع نهاية الثراية

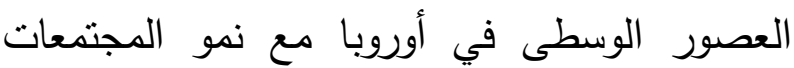
الفيدرالية وتطورها، وتطور عمل الدواوين الأميرية، ثم اختراع الطباعة وتتزايد كم المكتوب بنكل كبير جداً، حينها فحسب بدأت الرواية الثفوية للتاريخ في

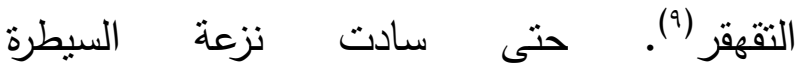
النصيَّة Textuality على عقول العلماء والمؤرخين، التي رفضت التعامل مع التاريخ الثنفوي إلا من بوابة الوثيقة المكتوبة('). وسادت في هذه الفترة تسمية الدصادر الثفوية والثراث الثعبي باسم الأساطير والخرافات الوعظية Didactic legends، التي تحمل مخزونات فلسفية ذات مغزى تعليمى، ولا علاقة لها بالتوثيق للتاريخ وتطور الظواهر الثقافية والاقتصادية والاجتماعبة والسياسية(") ولم بعد الاهتئمام بالرواية

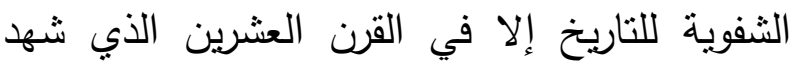

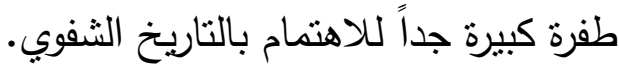
ץ- التاريخ الثفوي في سياق الاهتمام العالمي

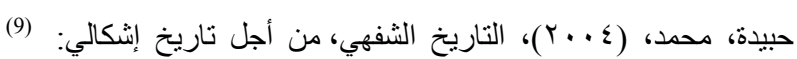
ترجمات مختارة، طا، منشورات كلية الآداب والعلون العلوم الإنسانية

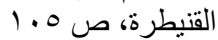

(10) Robert Lowie, Oral Tradition and History, American Anthropologist, Vol. 17, No. 3 (Jul. - Sep., 1915), pp. 597-599.

المقرحي، ميلاد، الرواية الثفهية والمصادر المدونة، الجزء الأول، (11)

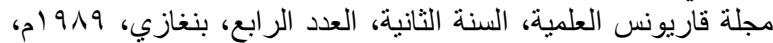
ص r
العالمية للحفاظ على النراث الثفوي أيا كان نوعه، وجدولت الحفاظ عليه كمحفز لمشاريع التتمية الوطنية والبشرية(") ، حيث لا تتمية مستدامة دون الحفاظ على الخصوصية الثقافية الدحفوظة في ذاكرة المجتمع ومنجزاته الفنية والأدبية، كما أنه لا مستقبل

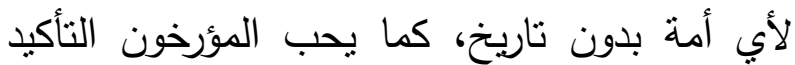

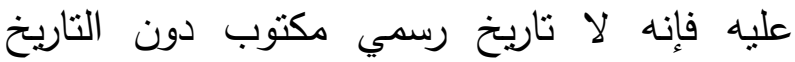
الثنفوي المروي والمنطوق، فالكنابة الناريخية التوثيقية

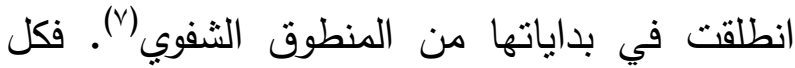
تواريخ العالم كانت خلال نشأتها وفي أساسها شفوية الفرية

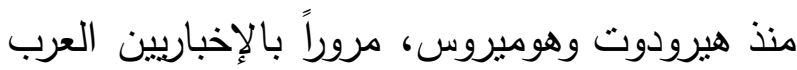

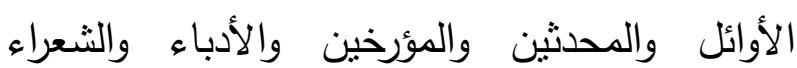
الأوائل الذين كتبوا مؤلفاتهم الثشهيرة اعتمادًا شبه تام الأن على الدصادر الثفاهية، بداية من ابن اسحاق وابن الفائ

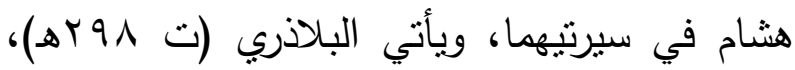

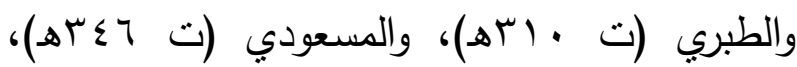
وابن خلاون (ت 1.1هـ) على رأس المؤرخين المسلمين الأوائل الذين اعتمدوا توثيق مادة كتبهم من مصادر شفوية كانت تثداول أحداث التناريخ نقلاً من جيل إلى جيل (^). ومن الواضح أنه لم يكن لاى المؤرخين الأوائل ما

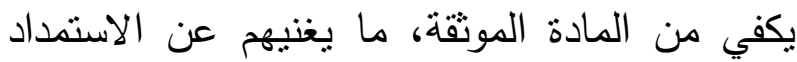

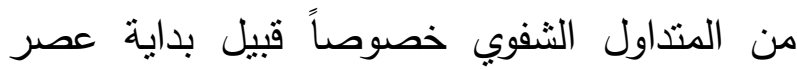

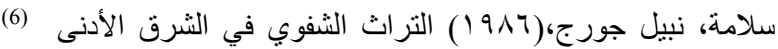

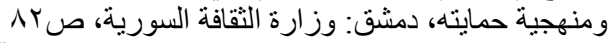

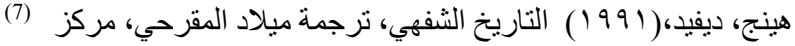

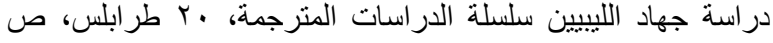
$r$.

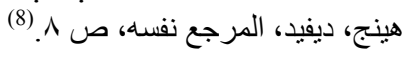


أدت النظرة غير الجدية عند المؤرخين عن التاريخ على رأسهم وليام إسحاق توماس، وفلوريان فيتولد

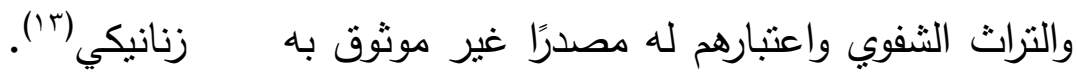

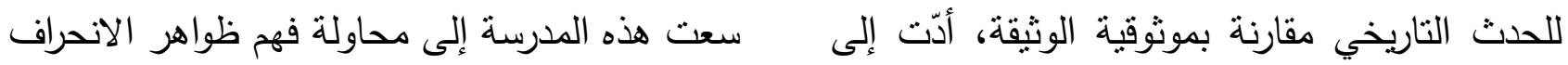

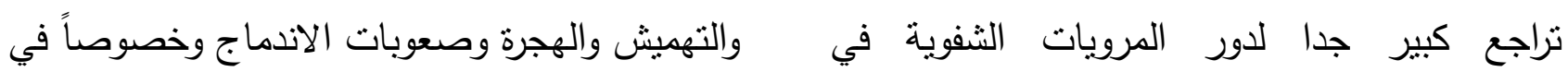
الطبقات المهشة كمجتمع السود في أحياء أمريكا

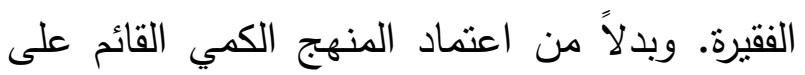
ملء الاستمارات، صاغ رواد هذه المدرسة ملامح المنهج الكيفي الذي يقوم على التحري الميداني والملاحظة بواسطة المشاركة والاستماع. وأصبح استدعاء الذاكرة الفردية وسيرة حياة الثريحة المهششة المدروسة وسيلة لإدرالك الواقع الاجتماعي في تداخله مع قيم وتطلعات الفئة المدروسة التي عادة تغيب في لني

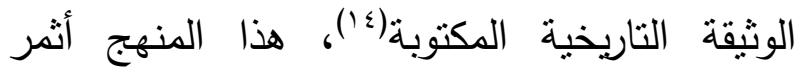

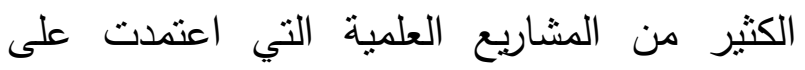
المرويات الثفوية، ولعل أثشرها الدراسة التي أثرفت الثنات عليها الحكومة الفيدرالية في منتصف الثلاثينيات حول ذاكرة العبيد السود وما تحمله من حكايات شعبية، قام المشروع على إجراء مقابلات شفهية مع الفلاحين والعاطلين عن العمل، والرقيق القدماء والهنود الحمر وآخرين(10).

لعب هذا النشاط التأريخي والسيولوجي دوراً بارزاً في واني

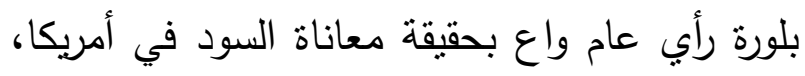
وبالتالي أنتج ما عرف في الستينات بحركة المطالبة

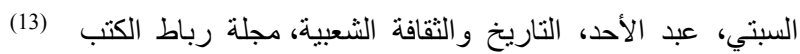

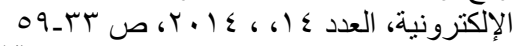

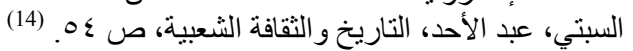

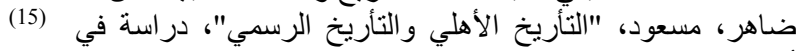

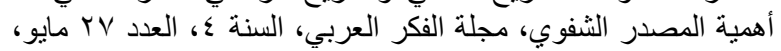

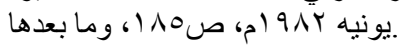

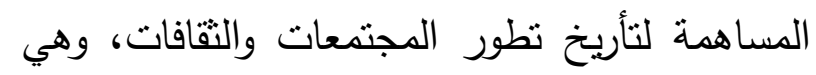
الثغرة التي نشط فيها علماء الفلكلور والانثروبولوجيا وابتعدوا بشكل ملحوظ في تتاولهم لها عن بعدها التأريخي ودروها في تنوثيق الأحداث، آخذين إياها إلى أبعاد سوسيوفيلولوجية تكاد تتجرد من أي علاقة لئي

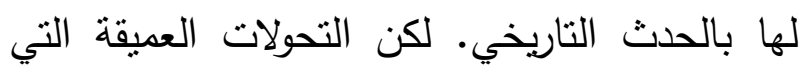

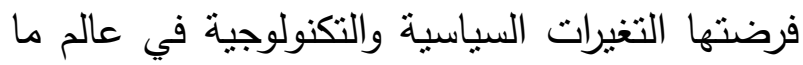
بين الحربين العالميتين، دفعت المهتمين بالتاريخ إلى إعادة النظر في القيمة العلية والتاريخية للمرويات والتراث الثعبي، نظراً لكون نوثيق يوميات الحربين

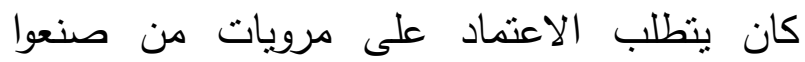
أحداثها من ضباط وجنود وشهود من عامة الناس. وكانت الولايات المتحدة الأمريكية السباقة لإطلاق جملة من المدارس والمشاريع العلمية التي تعتمد الرواية الثفوية مصدرا لها لرسم تفاصيل وقائع الفترات التاريخية وأحداثها من أفواه من عايثوا هذه الأحداث(ץ')، فنشأت نتيجة ذلك مدرسة شيكاغو السوسيلولجية في منتصف العشرينات على يد رواد كبار حاولوا استعمال الرواية الثفوية كمصدر لتحليل التحولات الاجتماعية في المجتمع الأمريكي، كان

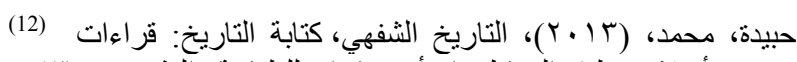

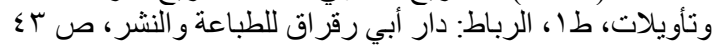


النشاط إلى مستوى تتظيم ملتقيات ودورات تدريبية تمكنت حتى سنة ولا ام من تسجيل مقابالات شفهية مع ( (...) مواطن من مختلف مناطق بربطانيا، ومن ثم تم إنشاء وحدة أرشيف الوثائق الصوتية التابعة لمحطة هيئة الإذاعة البريطانية (BBC) الثفهي تتمتع بحقوق ملكية محفوظة. كما فتح هذا النشاط المكثف الباب واسعاً أمام المبادرات الفردية، حيث دعت هيئة الإذاعة البريطانية كافة الشعب البريطاني بالمساهمة في التاريخ الثفهي عن طريق إثراء الهيئة بالأشرطة المنزلية التي تم تسجيلها إبان الحرب العالمية الثانية(9'). هذا الزخم مهر لتأسيس جمعية التاريخ الثفهي ببريطانيا سنة سو9 (م، التي عملت على تكثيف نشاط المقابلات والتسجيلات مع كافة طبقات المجتمع من العمال والفلاحين والسياسيين وسكان القرى والبوادي. وبرز في خضم هذا النشاط اسم المؤرخ والسوسيلوجي البربطاني الكبير جورج إيوارت ايفانز الذي بات (أبو التاريخ

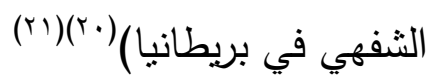

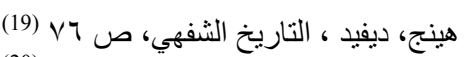

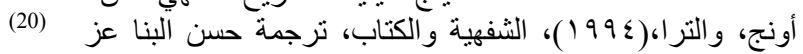

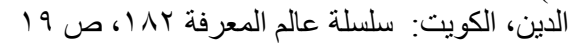

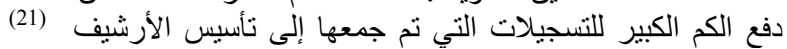

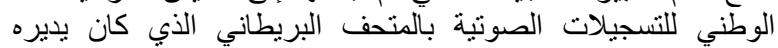

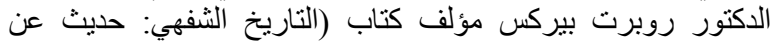

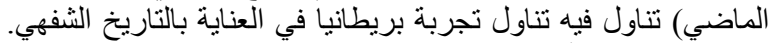

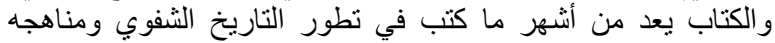

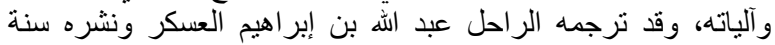

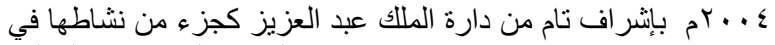

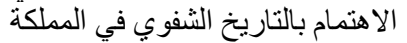

بالحقوق المدنية للسود والحركات النسائية وموجات الاحتجاج الطلابي التي شهدتها الجامعات الأمريكية ومتية ضد حرب الفيتتام("). تلت هذه المدرسة في الظهور مدرسة أخرى اثتهرت بمدرسة "تيار كولومبيا "التي أسسها الصحفي والبيوغرافي الألمريكي آلان

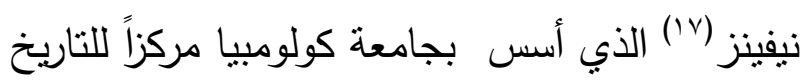
الثفوي سنة 9 1 1 رفقة زميله لويس ستار ، وارتكز منهج هذا المركز على جمع وتسجيل وتخزين الثهادات الثفوية للنخب السياسية والعسكرية والاقتصادية والعلمية والثقافية، التي أسهمت إسهامًا فعالاً في صناعة الأحداث في الولايات المتحدة

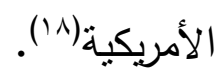

انتقلت هذه النزعة نحو اعتماد المصادر الثفوية في الكتابة التاريخية إلى بريطانيا في مرحلة منأخرة نوعاً

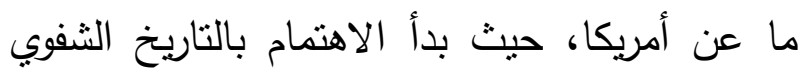
في منتصف الستينات كتأثر تام للنشاط الذي ولدته

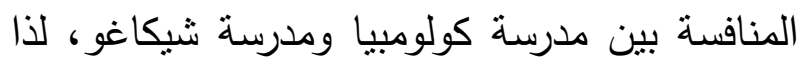
توجه الباحثون البريطانيون إلى الاشتغال على "تاريخ اجتماعي جديد "اهتم بدراسة الحياة اليومية للشغيلة. هكذا ساهم انفتاح الباحثين البريطانيين على التاريخ

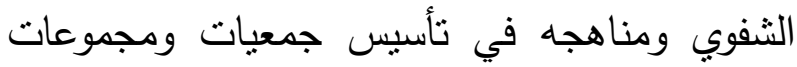
بحث حول التاريخ الثفوي، ومجلات كمجلة (حولية التاريخ الثفوي) التي تأسست سنة 979 (م. وانتقل

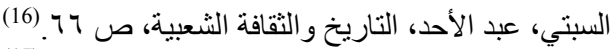

ولدت فكرة تأسيس مدرسة كولومبيا عند آلان نيفينز كنتيجة لنشاطهة

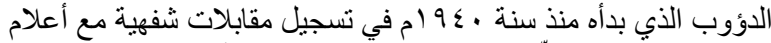

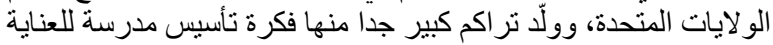

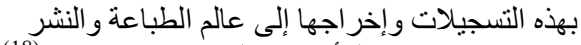

فانسينا، يان، المأثور ات الثفاهية، ص ص ؟ه الثباعة (18)
} 
والمجتمعات التي تخضع للوصاية الثقافية

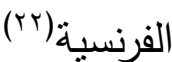

\section{r- التاريخ ي في السعودية}

بدأ الاهتمام بالتاريخ الثفوي في السعودية مبكراً عبر اهتمامات المستشرقين بلغات وعادات المنطقة العربية التي كانت جزءا من بحوثهم في تاريخ اللغات

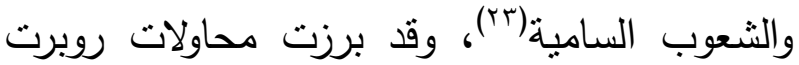
مونتان Robert Montagne كأول محاولة فردية اهتمت بتدوين سوالف، وقصص، وقصائد أبطال، وأعلام البدو من شمر في شمال السعودية، مثل:

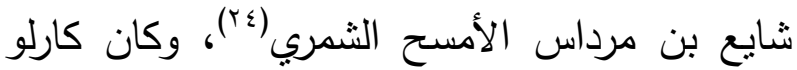
لاندبرج Carlo Landberg قد سبقه في نشر بعض قصائد الثعر النبطي التي يروي أمجاد الصحراء

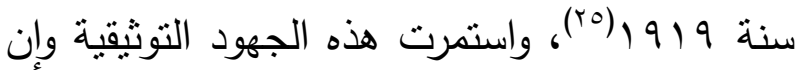

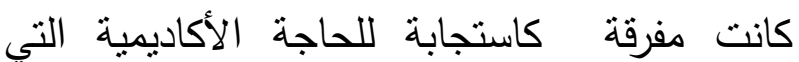
اقتضنها مناهج التدريس في الجامعات الغربية، ولعل أول عمل غربي متكامل يمكن اعتباره تدوينا وجمعا للتاريخ الثفوي في السعودية هو كتاب: تاريخ قبيلة

حبيدة، محمد، التاريخ الثفهي، ص ص 0 ؛ (22)

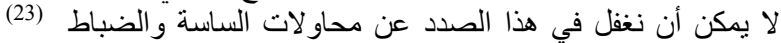

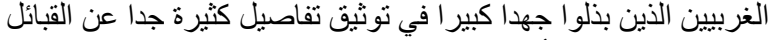

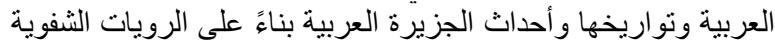

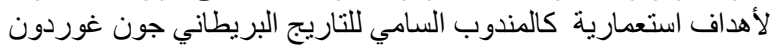

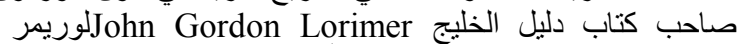
الموسو عي ذي المجلدين الذي طبع سراً من طرف الحكومة البريطانية

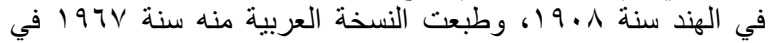 قطر.

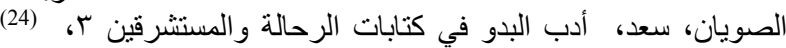

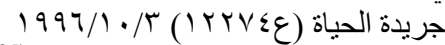

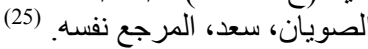

أما في فرنسا التي تعتبر مهد مدارس الكتابة

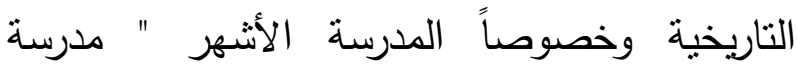
الحوليات"، فقد تأخر فيها الاهتمام بالتاريخ الثفوي

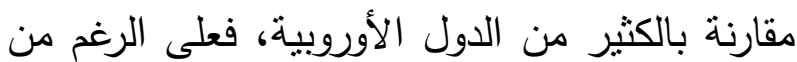

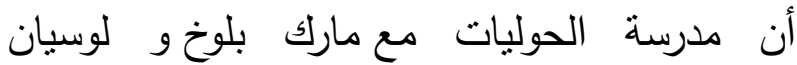
فيبر كانت من أوائل المدراس التاريخية التي كسرت

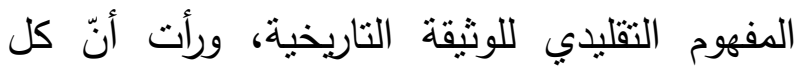

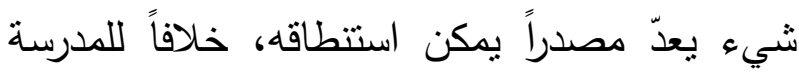
الوضعانية التي قدت الوثثية المكتوبة، إلا أن

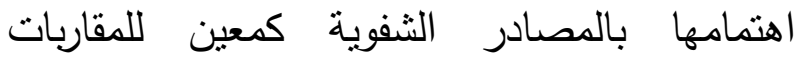
التاريخية تأخر إلى فترة الثمانينيات، أي مايزيد على بلى الثين • Vنة من نشأة هذه النزعة في الولايات المتحدة.

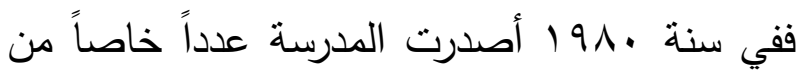
مجلتها الثهيرة مجلة "الحوليات: اقتصاديات، مجتمعات، حضارات " تحت عنوان":الأرشيفات الثفهية: تاريخ آخر"، اعترفت فيه بشكل رسمي

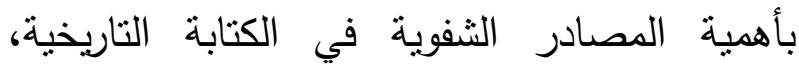
وانطلاقاً من هذه الخطوة انطلق الإنتاج التاريخي الفرنسي في الاهتمام بهذا المصدر الحيوي، وكان من ثرات هذا الاهتمام المشروع المعرفي الذي أطلقه المركز الوطني للبحث العلمي بباريس تحت مسمى "الرواية الثفهية والهوية الثقافية"، الذي مهد لكافة المشاريع العلمية التي تلته والذي جعل من

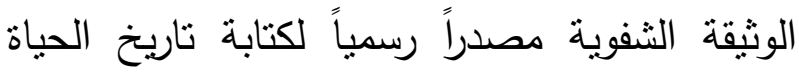
الاجتماعية والاقتصادية والسياسية للمجتمع الفرنسي، 
ونشر سنة \991، وخصص المجلد الثاني لشليوح بن ماعز العطاوي وشعراء آخرين وصدر سنة وهنة 1990، وخصص المجلد الثالث لأربعة شعراء دواسر، وهم: ابن بتلا، والدندان، ونابت بن ظافر، وبختيان بن ضافي، وقد صدر هذا الجزء سنة

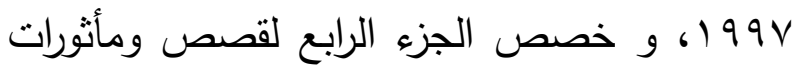
من قبيلة الدواسر وصدر سنةr ...r، و صدر الجزء

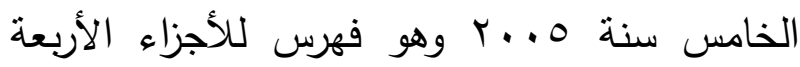
الأولى. و من الإنجازات القيمة والثرية في هذا لهاء التهن

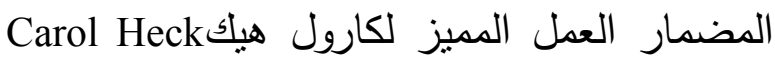
تحت عنوان " ذكريات وانطباعات عن المملكة العربية السعودية وأرامكو من ثلاثثيات القرن العشرين

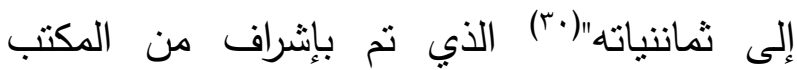
الاقليمي للتاريخ الثفهي بجامعة كاليفورنيا، جمعت بـانه فيه كارول هيك في خمسة أجزاء ضخمة شهادات ثمانية أمريكين من الكوادر الكبرى التي كانت تدير وتترف على صناعة البترول في السعودية، وقد ورد العمل في خمسة مجلدات ضخمة، واعتمدت فيها المنهجية التاريخية العلمية في التعامل من النص الثفوي، ويكاد أن يكون هذا العمل أول عمل اهتم

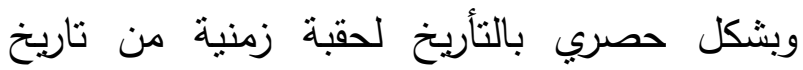
المملكة باعتماد تام عن الرواية الثنفوية، وبمنهج علمي صرف.

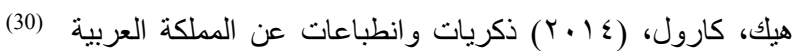

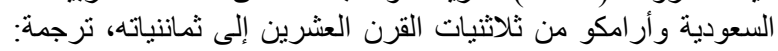

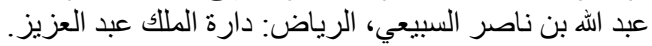

Bruce Ingham الظفير الذي أعده بروس أنغام

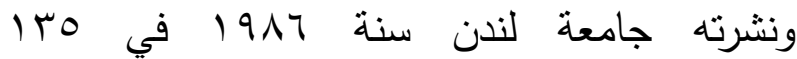
صفحة(Tr(Y)، وقد كان لبروس مساهمات أخرى تمنلت في مقالات منشورة وثق فيها المصطلحات الخاصة

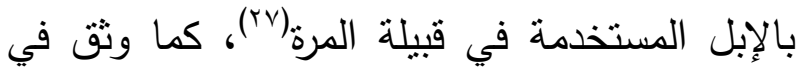
بعضها بعض السوالف الثفهية التي تحكي أحداثاً

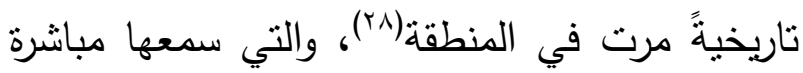
من البدو في الجزيرة العربية، ختم هذه الجهود الغربية الباحث الهولندي مارسيل كوربرسهوك Marcel Kurpershoek، الذي يعتبر أشهر غربي اهتم بتوثيق التاريخ الثفوي في المملكة العربية السعودية، وقد استفاد مارسيل من احتكاكه الطويل بسكان المملكة بعد أن انتدب من طرف بلاده للعمل في سفارة بلاده

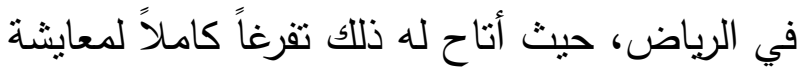
قبائل البدو وإتقان لهجاتهم وعاداتهم، وبالتالي توثيق تواريخ وأنثعار الكثير منها، ويعد كتابه "البدوي

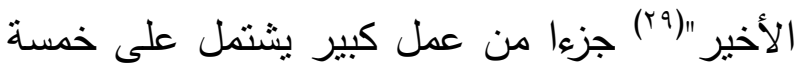
مجلدات، خصص الجزء الأول منه للشاعر الدندان

(26) Ingham, Bruce and bin, Atiyyah Qabilat al Dhafir Dirasa Lughawiyyah Muqarinah. Kuwait. (1995)

(27) Ingham, Bruce (1997) Arabian Diversions: Studies in the Dialects of Arabia. Ithaca Press.

${ }^{(28)}$ See: Ingham, Bruce Introduction to Simple Etiquette in Saudi Arabia and the Gulf States. Global Books Ltd. 1995. And Najdi Arabic: Central Arabian. John Benjamins, 1994. And 'Information structure in the Najdi dialects.' In: Owens, Jonathan and Elgibali, Alaa, (eds.), Information Structure in Spoken Arabic. London; New York: Routledge, 2010. pp. 7592. (Routledge Arabic Linguistics Series)

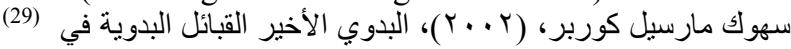

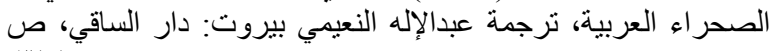
ب 1 
سعود في كتابه تاريخ ملوك أسرة آل سعود منذ

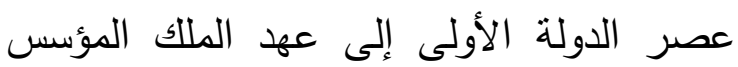

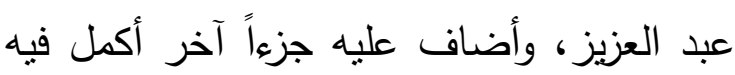

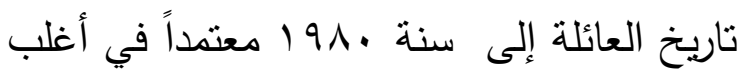

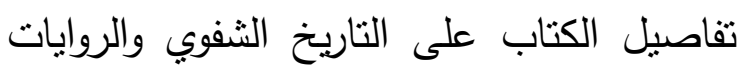
المتداولة بين أفراد العائلة المالكة وكبار المثقفين

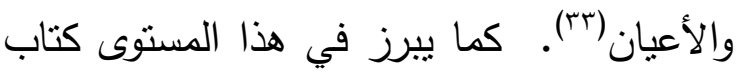
"الأمير عبداله بن عبد الرحمن بن فيصل فئل 1ابا- - 14اهـ" الذي ألفه صلاح الدين المنجد سنة 1977 مستنداً على الروايات الثفهية عن حياة وإنجازات الثقيق الأصغر

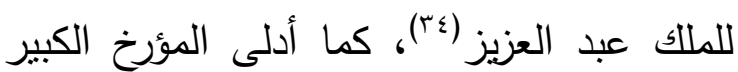
عبداله العثيمين بدلوه من خلال محاولاته لتوثيق الثعر النبطي كوسيلة من وسائل التوثيق التاريخي التي عاشتها الجزيرة العربية في كتابه:" نشأة إمارة آل رشيد".(ro) وآخر المحاولات الفردية جهود عبد اله بن ابراهيم العسكر الذي انبرى لموضوع توثيق التاريخ الثفوي وكرس أكثر جهده

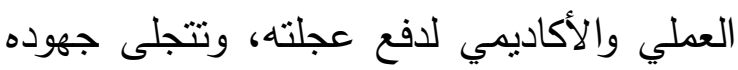
في هذا المضمار من خلال كتاباته كمقال "المدلول الأسطوري لدعوة مسيلمة بن حبيب
أما عن الجهود المحلية السعودية في توثيق التاريخ الثفوي في السعودية فيمكننا تلمس مستويين منها، وهما:

• المستوى الفردي: تبرز في هذا المستوى المبادرة المبكرة جداً التي واكبت بداية الاهتمام الغربي بالتاريخ والتراث الثنفوي للجزيرة العربية(1)؛ في كتاب "نبذة تاريخية عن نجدي" الذي أملاه ضاري بن فهيد الرشيد على الأديب اللبناني وديع البستاني أثناء رحلة علاجه في

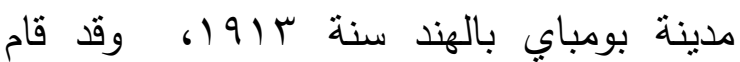
المؤرخ الكبير حمد الجاسر بتحقيقه ونشره سنة بالة 1974، وهو يعدّ أول محاولة توثيق للتاريخ الثفوي في الجزيرة العربية من قلم عربي سرد فيها بن فهيد كل ما سمعه من آبائه وكبار مجتمعه من تواريخ وتفاعلات سياسية واجتماعية

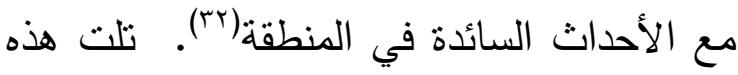
المبادرة المبكرة مبادرة للأمير سعود بن هذلول الاحل آل سعود في كتاب (تاريخ ملوك آل سعود) الذي سبي ألفه سنة . 97 ام، و الذي يعدّ من أهم المبادرات المحلية لتوثيق التاريخ الثفهي المحلي، ويتتاسب تاريخياً مع بداية الاهنمام البريطاني بالمصادئ لئري الثفوية في الكتابة التاريخية. عرض الأمير

من المحاو لات المبكرة جدا محاولة ابن دعيج لتوثيق تاريخ حملة (31)

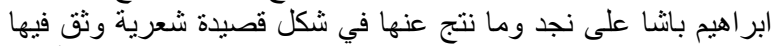

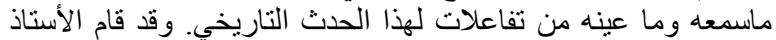

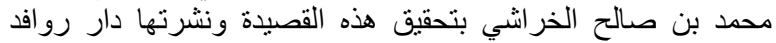

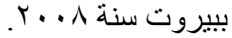

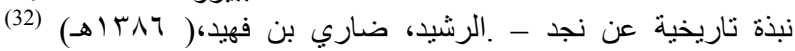
الرياض: دار اليمامة للبحث و النشر. 
انثروبولوجية"(·؛) الذي ارتكز فيه على المادة الثفوية

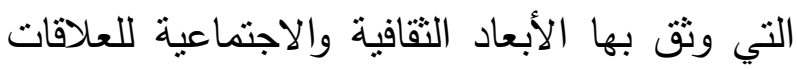
في الصحراء العربية وعلاقة البادية بالحضر ومفاهيم

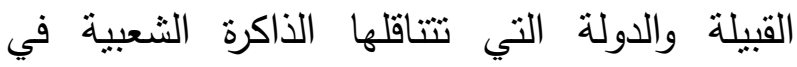

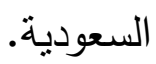

- المستوى الرسمي والمؤسساتي: برز الاهتمام

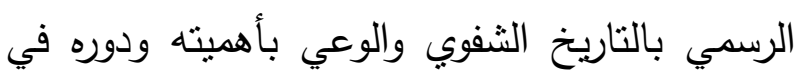

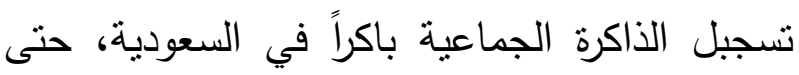
قبل ظهوره في العديد من الدول العربية الأخرى، وتتمنل أول مبادرة رسمية في خطوة مركز أبحاث الحج التابع -حينها- لجامعة الملك عبد العزيز الذي أسس سنة 19V0 فريق عمل ضم ثلة من علماء

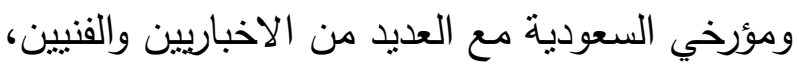
لتسجيل مذكرات المعدرين من ذوي العلاقة بالحج

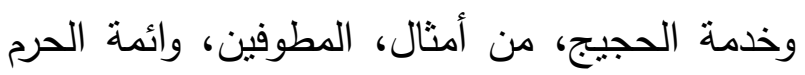

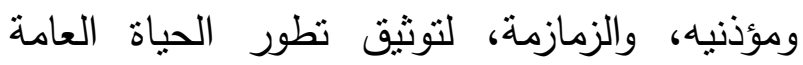
وتطور خدمات الحج عبر الحقب التي عاشوها

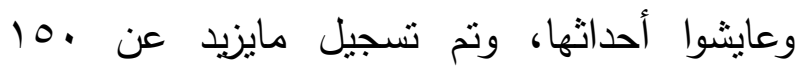

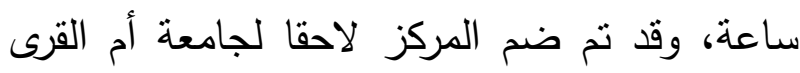

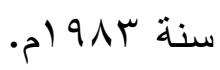

ثم بادرت مكتبة الملك فهز الوطنية إلى تشثين دورها الريادي في نتثيق التاريخ الثفوية سنة §99 19، حيث بدأت في سلسلة مطولة بتسجيل مقابلات مطولة مع الوجوه التقافية في السعودية وقد

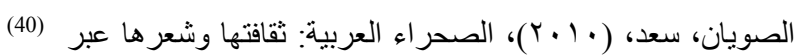

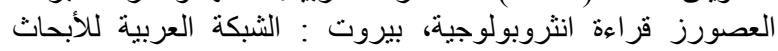
و النشر. الحنفي"("r) الذي حاول فيه تفسير دعوة مسيلمة بن حبيب الحنفي، المشهور بمسيلمة الكذاب من دمعن منظور أسطوري، وقد توصل من خلال تحليل

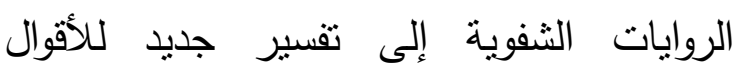

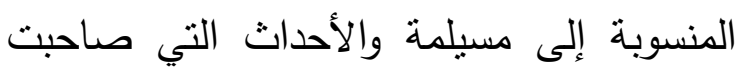
ظهوره. وتبرز في هذا المضمار المساهمة الرائدة للاكتور سعد الصويان الذي يعدّ رائد توثيق التاريخ والتراث

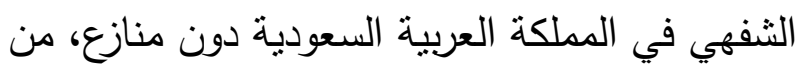

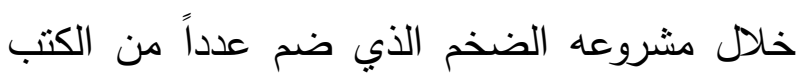
التي بناها الصويات على المرويات الثفوية ككتابه " أيام العرب الأواخر: أساطير ومرويات شفهية في لثات التهات

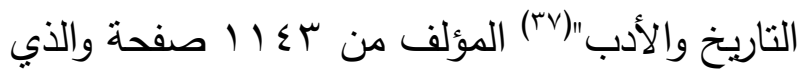
بدأ في جمع مادته سنة ب1911، وسجل في سبيل ذللك مئات الساعات من محكيات شمال الجزيرة وخصوصا قبائل شمر وبني رشيد والطرفا وعنزة

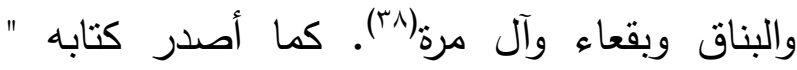

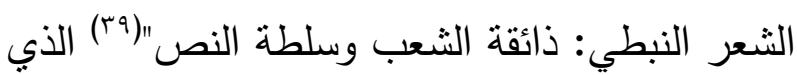
حدد فيه الأطر المنهجية لتدوين التاريخ الثفهي وجمع فيه الكثير من النصوص والمرويات الثفوية، وييرز من بين إسهاماته كتابه الماتع: " الصحراء العربية: ثقافتها وشعرها عبر العصورز قراءة

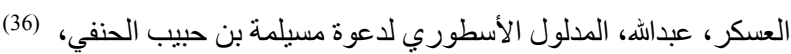

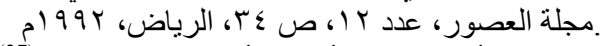

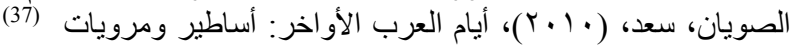

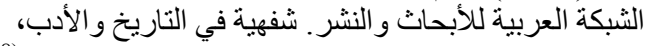

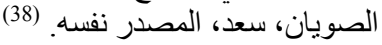

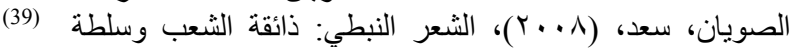
النص، الرياض: النبط: ذأفساق للنشر و التوزيع.
} 
عقت أول جلسة تسجيل مع الأستاذ عبد الكريم إلى تدوين التاريخ الثفوي لـناطق الثمال انطلاقاً

من حائل(؟r)

كما تبرز من بين المحاولات الرائدة مشروع جمع الثعر النبطي من مصادره الثفهية الذى نم بتمويل

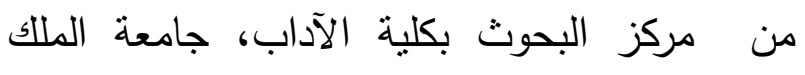

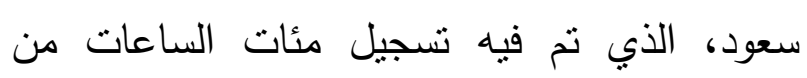
تسجيل مقابلات شفهية مع المعمرين من رواة البادية

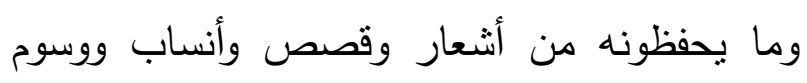

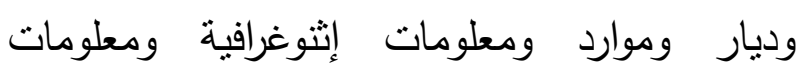
تاريخية عاشوها.

ولعل النشاط التوثثي للتراث الثفوي والمرويات

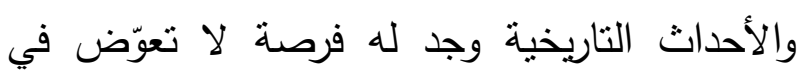

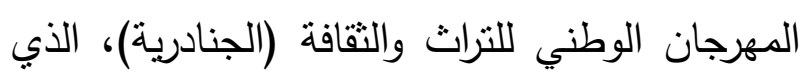
انطلق منذ قرابة .r سنة وقامت اللجان التقافية المسؤولة فيه بزيارات ميدانية للمواقع الأثرية

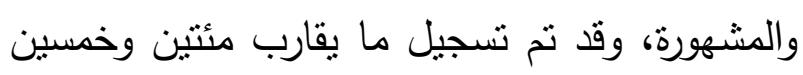

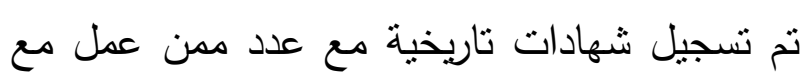
الملك عبدالعزيز، وقد تم تفريع تلك المقابلات وضمها في كتاب صدر من المهرجان الوطني

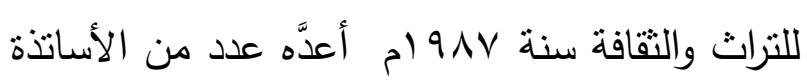

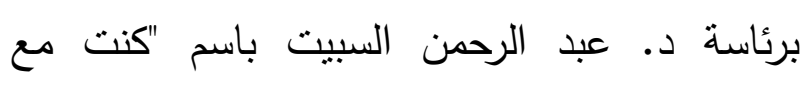

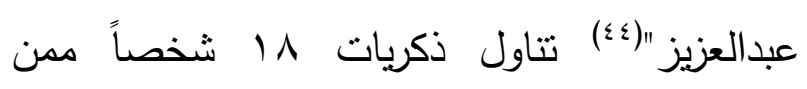

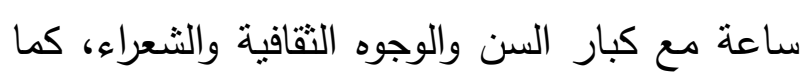

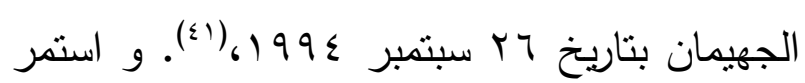

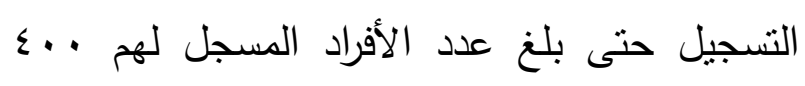

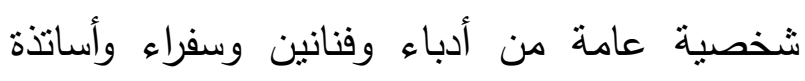
ومديري جامعات ووزراء، وامتدت فترات التسجيل مع ونع بعضهم إلى تسع ساعات كاملة|(זی). ولعل المبادرة الأبرز هي تلاك التي قامت بـاعل بهات دارة

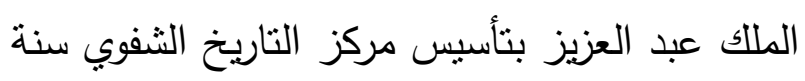

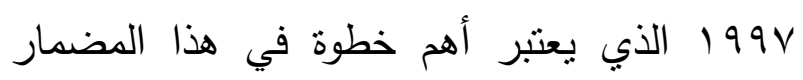
نظراً للأهمية التي تحظى بها الدارة والنشاط الثقافي الكبير لها في حفظ تاريخ المملكة العربية السعودية، وقد حددت مهام المركز في مجموعة من النقاط، منها: حصر أسماء المعاصرين مدن لهم إسهام في فهري الحياة العامة في المملكة، ثم إجراء مقابلات حصرية

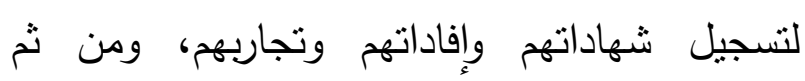

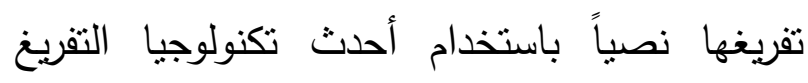

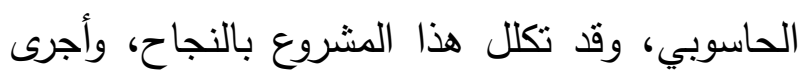

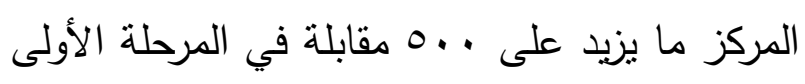
من خطة عمله، كما تمكن المركز من جمع أكثز من م ب ألف وثيقة أصلية ومصورة نوثق لأحداث ثقافية وسياسية في تاريخ المملكة الحديث، كما تم تصوير ما يزيد على ألف مشهد للمعالم الأثرية والتاريخية التي تزخر بها المملكة. وقد نم تششين

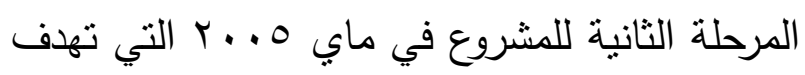

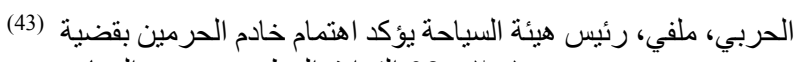

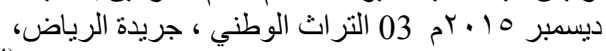

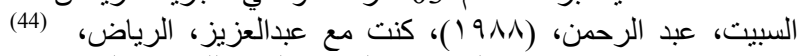

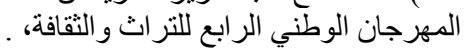

\footnotetext{
القشعمي، محمد عبد الرزاق، التاريخ الثفوي وأهميته، جريدة (41)

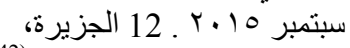

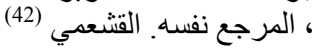


صاحبوا الملك المؤسس وتم التسجيل معهم عام تاريخها الثفوي والاهتمام به صوناً له من الضياع والاندثار .

ع - التاريخ الثفوي لجدة أ-كتب الرحلات في القرن التاسع عثر: تأريخ مبكر للمشاهدات والمرويات الثعبية كان لوقوع جدة تحت ظل العاصمة المقسة مكة المكرمة أنثره الواضح في صيرورة العلمية التأريخية لتاريخ هذا الثغر الهام في تاريخ الحضارة الإسلامية، وانعكس هذا الأثر في بعدين متتاقضين عملا سوياً على صناعة فرادة مدينة جدة في كتب التاريخ وهما: - تأخر تخصيص جدة بالكتابة والتدوين نظرا لعكوف أغلب المؤرخين على الكتابة والتأريخ لمكة المكرمة، ولعل أول عمل علمي خصّ جدة بمحتواه يعود إلى فترة متأخرة جداً إلى القرن العاشر منمثلاً

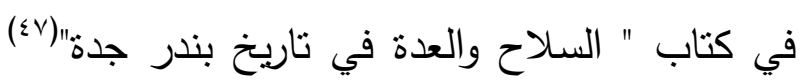

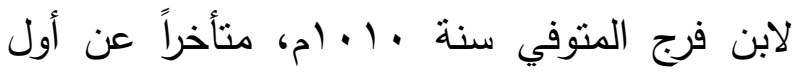
عمل خصص علمي خصص لتاريخ مكة بحوالي مائتين سنة (ఓ人)

- حشد الموقع الجغرافي لجدة وقربها من مكة المكرمة اهتمام الرحالة والمؤرخين المسلمين القدامى لهي

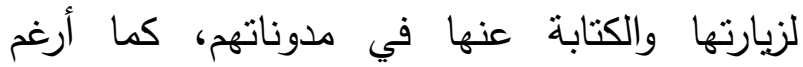

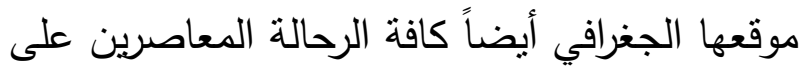

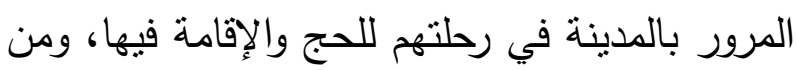

\footnotetext{
لابن ظهيرة المتوفى عام 91 هـ كتاب أسماه (تاريخ جُدَّة) إلا أن (47)

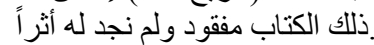

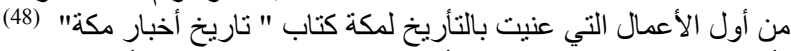

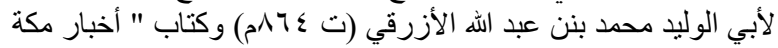

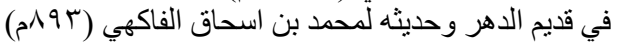

ولا يمكن أن نغفل في هذا المضمار؛ المشروع التوثيقي للثقافة التقليدية في المملكة العربية السعودية الذي تم بتمويل من الأمير سلطان بن عبد العزيز وإدارة الدكتور سعد الصويان وصدر عن دار الدائرة للنشر والتوثيق في إثنى عشر مجلداً تتناول كافة أنثكال الحياة والثقاليد في المملكة، وقد النئ اعتمدت المصادر الثفوية كأحد أهم مصادر هذا المشروع

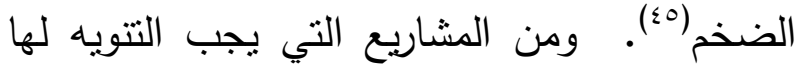
هي مبادرة برنامج الأمير محمد بن فه للاراسات

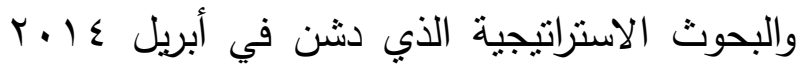

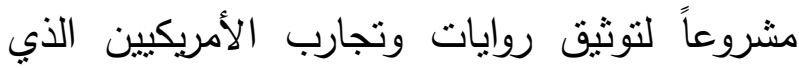

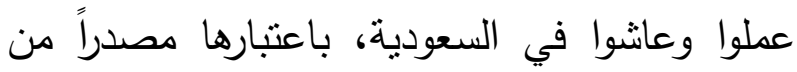
مصادر التاريخ الثفوي لنطور المؤسسات والحياة المهنية في الدولة. هذا المبادرات والمشاريع التي شهدتها لهمله المملة وصلت في مجملها حسب إفادة المؤرخ عبد الله ابن

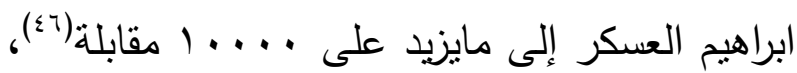
أجريت مع أعلام المملكة من سياسيين واقتصاديين

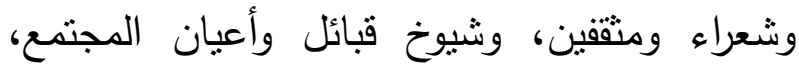
وحتى من عامة الناس، مما يضع المملكة في صدارة

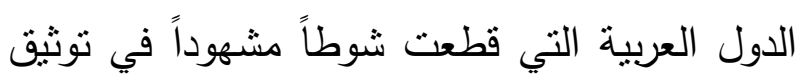

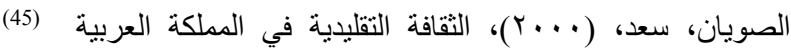

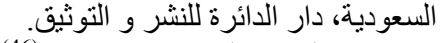

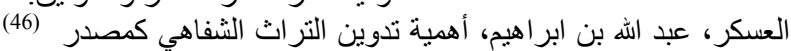

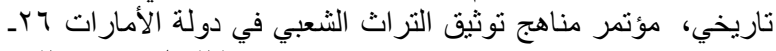

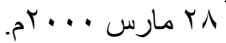


ثم الكتابة عنها، مما أثرى كتبهم بالكثير من تفاصيل القرنين 19 و 19 أكثر مما تجده في كتب الرحالة الغربيين.

وفي سياق الحديث عن تدوين التاريخ الثفوي لمدينة

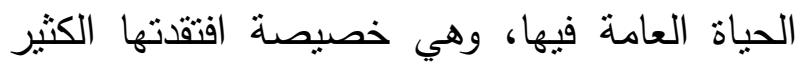
جدة في القرن العشرين، يجدر بنا التعريج على تاريخ من حواضر العالم الإسلامي.

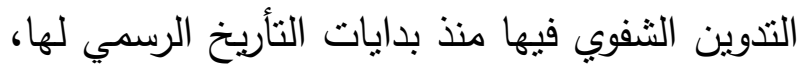

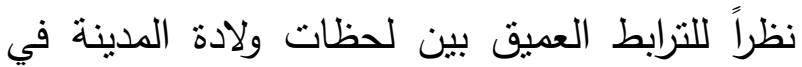
القدم وبين تراثها المعاصر ، ونظرا لمحافظة مدينة جدة -منمثلة في مدينتها القديمة- على الكثير من الخصائص التراثية والحضارية والثقافية التي ترعرت في المراحل الأولى لتطورها. بحيث بمكن العودة بالكثير من القضايا المعاصرة في الثقافة الثعبية الجداوية وبسهولة إلى عدة قرون مضت من خلالي ما دونته كتب الرحالة عن مجتمعها وأنماط الحياة فيها، بداية من الرحالة الثهير محمد بن أحمد الثدانه

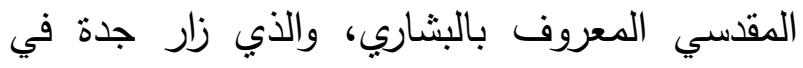
القرن العاشر الميلادي ودون عنها في كتابه " أحسن

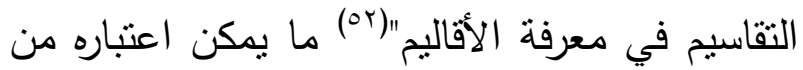
أقدم النصوص التوثيقية للحياة العامة في جدة، نلاه في الترتيب الزمني ما كتبه ناصر خسرو في كتابه "

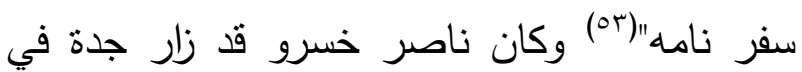
القرن الحادي عشر الميلادي، وكتب عنها ووصف عمرانها وسكانها ونقل الكثيرمما سمعه من سكانها،

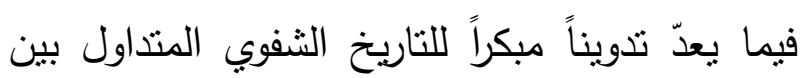

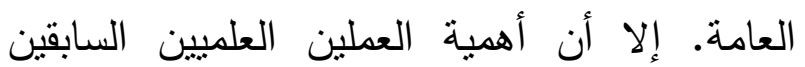

\footnotetext{
المقدسي، محمد بن أحمد،( (991))، احسن التقاسيم في معرفة الأقاليم، (52)

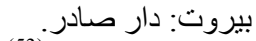

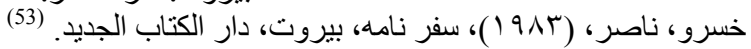


الحضارة والتطور نحو أوروبا ودشن فيه ما يعرف بعصر الاكتشافات الجغرافية، وكانت البداية مع الرحالة الإيطالي لودفيكو دي فارتيما الذي وصل

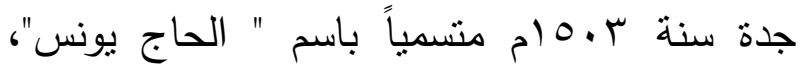
ودون الكثير من الملاحظات والمشاهدات عن الحياة الدينية والاجتماعية فيها في كتابه " رحلة فارتيما"(ov) وبعتبر المؤرخون الرحالة لود فيكو أول

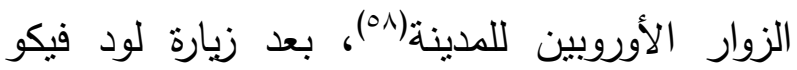
ستشهد المدينة حملة مكثفة من الزبارات الغربية تواكبت مع الحملات التوسعية التي كان يشنها البرتغاليون والإسبان في المحيط الهندي وبحر العرب، والتوسعات الفرنسية والبربطانية التي ورثت جهود الدولتين السالفتين، ولعل وصول الرحالة الإنجليزي الثاب جوزيف بتس لمدينة جدة سنة 1 1 ام وكتابته عنها في كتابه " رحلة جوزيف بتس"(ه9) يمكن أن يؤرخ لبداية الاهتمام الإنجليزي والفرنسي بالمنطقة العربية والعالم الإسلامي عموماً. لم يكتف الأوروبيون في سعيهم للتعرف على البلاد العربية بجهود المغامرين والرحالة المفردين، بل دشنوا مرحلة جديدة من محاولة التثاقف بين العالمين

دي فارثيما، لود فيغو، ( ع99 1)، الحاج يونس المصري: رحلات (57) فارثيما، ترجمة عبد الرحمن عبد الله الثيخ، القاهرة: الهيئة المصرية

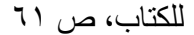

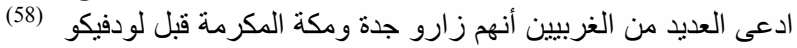

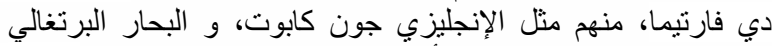

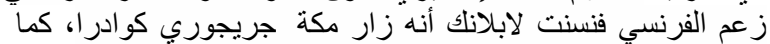

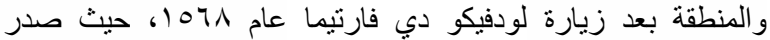

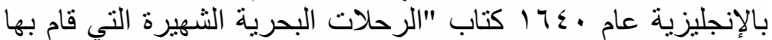

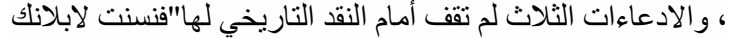

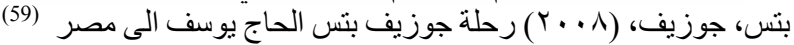

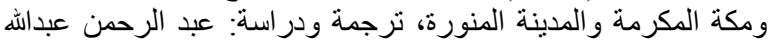
الثيخ، القاهرة: الهيئة المصرية ودرية العامة للكتاب.
تجاوزتهما شهرة زيارة الرحالة الثهير ابن جبير إلى جُدة في القرن الثاني عشر ، الذي ترك في في كتابه "

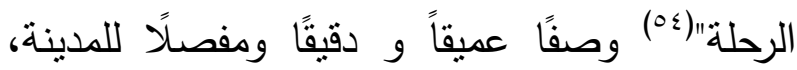
وتحدث عن مساكن جدة وعن أهلها وعن فنادقها

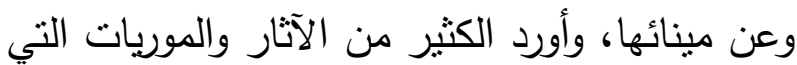
سمعها من سكان المدينة. ثم تلى عمل ابن جبير من حيث الأهمية والتزتيب الزمني ما كتبه الرحالة ابن الندئه المجاور الذي زار جدة في القرن الثالث عشر؟؟ ووضع أول خريطة للمدينة في تاريخها في كتابه " تاريخ المستبصر "(00).

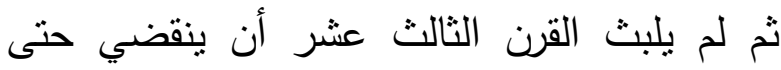
حظيت مدينة جدة بعدد من الزيارات من عميد الرحالة في التاريخ الرحالة ابن بطوطة الذي دون

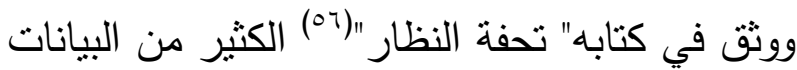
والأوصاف والتفاصيل التي غابت في في رحلات السابقين له من الرحالة العرب. بعد زيارة ابن بطوطة انفتحت المدينة وتاريخها عن جيل جديد من الرحالة والكتاب الذي بدءوا يتدفقون على المدينة، وساهموا بشكل كبير في توثيق العديد من تفاصيل الحياة العامة فيها من خلال مشاهداتهم وملاحظاتهم، هذا الجيل تمنت في الرحالة الغربيين الذي تسلموا -كما

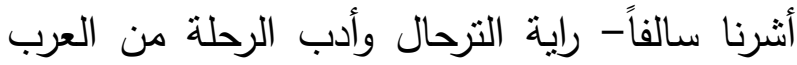
في بداية القرن السادس عشر، الذي مال فيه ميزان

ابن جبير، محمد بن أحمد، (ד/9 ())، رحلة ابن جبير، بيروت : دار (54) و مكتبة الهلال، ن دارل.

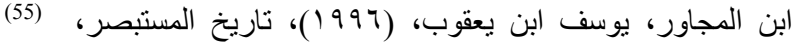
القاهرة : مكتبة الثقافة الدينية.

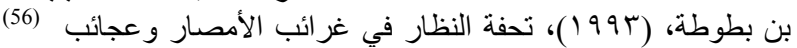
الأسفار، طنجة، المغرب: مدرسة الملك السعدي. 
التفاصبل التي أهملها سابقوه(rا) ولكونها كتبت سنة ع ا1 ام في بداية القرن التاسع عشر، وهو المرحلة التاريخية الأهم في تاريخ المنطقة الحديث، كما أن كون الكاتب كان مسلماً جعل من كتابته عن جدة الكثير من روح المصداقية والبعد عن التحامل والتنميط. ولم يتوقف سيل الكتابة الأوروبية عن المدينة بل تواصلت وكثقت في أواسط القرنين التاسع عشر والعشرين نظراً لتطور وسائل المواصلات وظهور الدول الحديثة في أوروبا ونشأة العلاقات الدبلوماسية بينها وبين الدولة العثمانية مما اقتضى وصول الكثير من الغربيين سياسبين كانوا أو مثقفين إلى جدة وغيرها من الحواضر كممثلين ديبلوماسبين لبلدانهم، ونورد هنا على سبيل الذكر زيارة الرحالة الفرنسي موريس تاميزبيه سنة عبما الذي خلا الكثير من المعلومات عن جدة في كتابه "رحلة إلى بلاد العرب"(๕؟)، وزيارة العميل الفرنسي ليون روش سنة اییام لجدة وكتابته عنها في كتابه " اثتان وثلاثون عاماً في الإسلام"(70)، وما كتبه الرحالة

من المعلومات الدقيقة والطريفة التي أوردها بيركهارت عن جدة أنه (63)

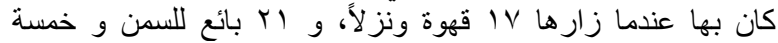

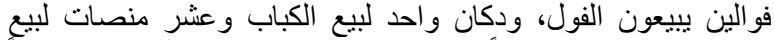

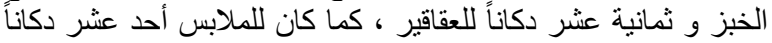

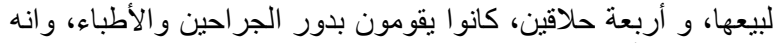

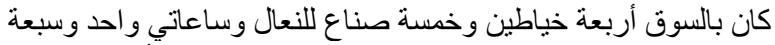

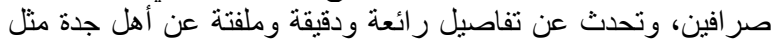

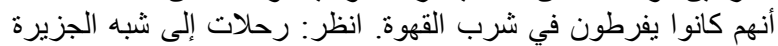
العربية

(64) Maurice Tamisier, (1840)Voyages en Arabie, séjour dans le Hedjaz, campagnes d'Assis, Paris: Louis Desessart.

(65) Léon Roches,(1884) Trente-deux ans à travers l'Islam: (1832-1864), Paris: Firmin-Didot.
جسدتها البعثة العلمية التي أرسلها الملك الدنماركي فردريك الخامس تحت رئاسة الرحالة كارستن نيبور سنة rVT ام وكان هدف الرحلة التعرف على الثعوب العربية وبلادهم، وكتب كارستن ومن معه من العلماء الكثير من تفاصيل الحياة العامة والتطور العمراني لمدينة جدة في الكتاب الذي كان نتاجه هذه الرحلة تحت عنوان" رحلة إلى شبه الجزبرة العربية

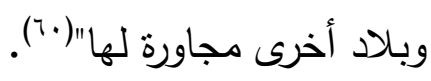
تطورت محاولات التعرف الغربي على جدة وما جاورها من البلاد العربية من مرحلة الكتابة والتوثيق، إلى مستوى التوظيف والاستلهام الفني، حيث يمثل الرحالة الإسباني دمنجو باديا لابلخ الثهير باسم " علي بك العباسي" هذه المرحلة وكان قد زار جدة سنة 1/1ام ورسم العديد من اللوحات خلد فيها مناظر من المدينة، ووثق في رحلته(آ) العديد من المشاهدات والتفاصيل عن الحياة الثقافية والاجتماعية والدينية للمدينة. إلا أن رحلة الرحالة السويسري جون لويس بيركهارت والموسومة ب: "

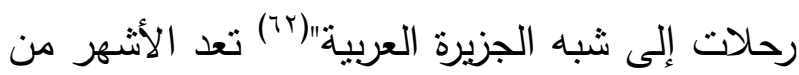
كل ما ذكرنا من الرحلات والكتابات نظراً لكونها تميزت بالعمق والتفصيل وتطرقت للعديد من

${ }^{(60)}$ Baack, Lawrence J. 2014)Undying curiosity. Carsten Niebuhr and the Royal Danish Expedition to Arabia (1761-1767). Stuttgart.

${ }^{(61)}$ Badía y Leblich, D.F.J. Voyages d'Ali Bey el Abbassi en Afrique et en Asie pendant les Années 1803, 1804, 1805, 1806, et 1807, Paris: P. Didot l'Ainé, 1814.

بيركهارت، جون لويس، (0 . . ب) رحلات إلى شبه الجزيرة العربية، (62) ترجمة هتاف عبد الله، بيروت: مؤسسة الانتشار العربي. 
وما دونه في كتابه" رحلتي إلى مكة"(V(V)، ورحلة الرحالة البريطاني المسلم وليام رينتارد وليامسون

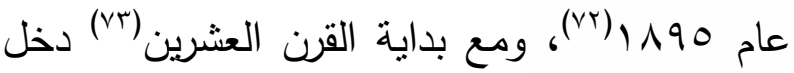
النساء حلبة الكتابة و التوثيق لجدة وتاريخها، فقد اشتهرت رحلة اللبدي إيفلن كوبولا الارستقراطية البريطانية التي كانت تعيش في الجزائر واعتقت فيها الإسلام وساعدها سفير المملكة العربية

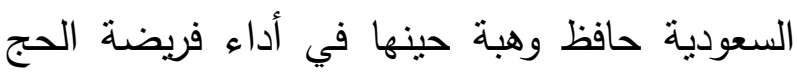
سنة سب91، وكتبت في رحلتها الكثير عن جدة

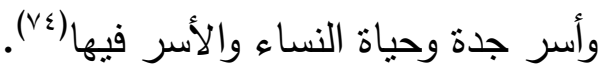
ب- القرن العشرين وانطلاقة تلدوين التاريخ الثفوي لتاريخ جدة لعله من الصعب للباحث عن تطور تدوين

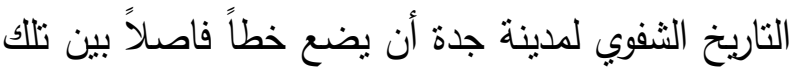
الكتابات التي اعندت المنهجية التاريخية المعهودة، وهي العودة إلى المصادر والمراجع لاستنطاق التاريخ ورسم ملامح الحياة فيها، وبين تلك التي اعتمدت تدوين التواريخ الثففية للمدينة والمتداولة بين كبار سكانها ومثققيها، نظراً

كورتلمون، جيل جرفيه، (r . . r)، رحلتي إلى مكة، ترجمة محمد (71)

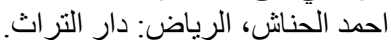

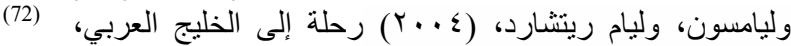

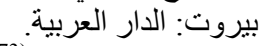

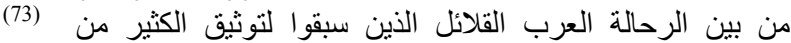

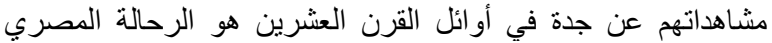

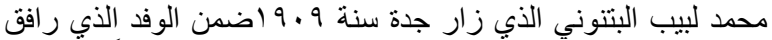

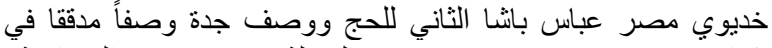

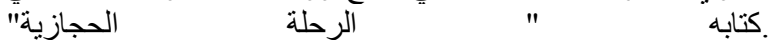

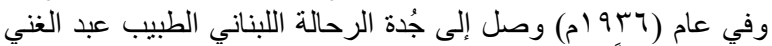

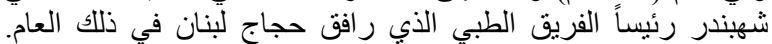

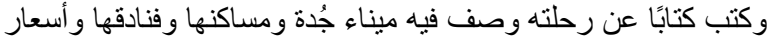
غرف هذه الفنادق ومعلومات أخرى مفيدة عن هذه ودهاء المدينة.

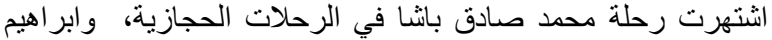
رفعت باشا في " مر آة الحرمين الرحت

(74) Lady Evelyn Cobbold, (2008) Pilgrimage to Mecca, Abu Dabai: Arabian.
البريطانبي الثهير رينشارد بيرتون سما1 عن جدة

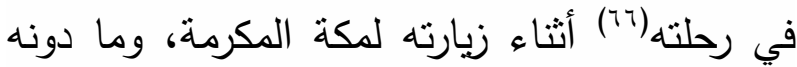
الرحالة الفرنسي شارل ديديه عن جدة في كتابه "

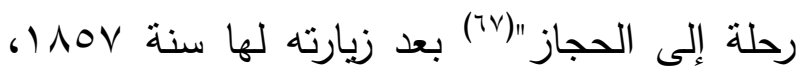
وزيارة الدكتور البريطاني هيرمان بكنيل عام

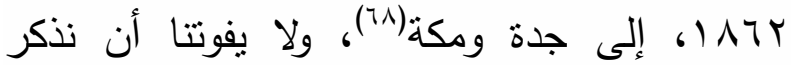
المستشرق الهولندي كرستيان سنوكهورخرونيه الذي أقام في مكة مدة سنة 1110 وكان كثثر التردد على جدة وصاحب الكثير من أعيانها وكتب بالتقصيل عن الحياة العامة فيها(79).

و كان الرحالة والضابط الروسي عبد العزيز دولثتنين الذي زار جدة في طريقه للحج سنة امش1 أول رحالة يفصل في المكانة الوظيفية للمدينة بالنسبة لمكة وخصوصاً في الحج، حيث أورد أسماء وكلاء المطوفين بجدة في ذلك الوقت، ووضح دولنتين إعداد الحجاج في جداول منظمة ووضع أسماء الإدلاء والمطوفين في جداول أخرى وبين أعمار بعض فئات الحجاج في عملية توثثقية رائعة

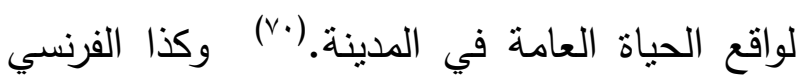
جيل جرفيه كورتلمون سنة .119 إلى جدة ومكة

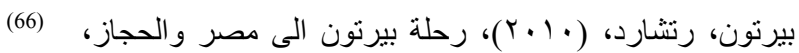
ترجمة وتعليق: عبد الرحمن عبداله الثيخ، القاهرة: الهيئة الهصرية العامة للكتاب

(67) Charles Didier (1985)Sojourn with the Grand Sharif of Makkah, Cambridge: Oleander Press.

${ }^{(68)}$ Edward Balfour( 1885) The cyclopedia of India and of eastern and southern Asia, London: B. Quaritch.

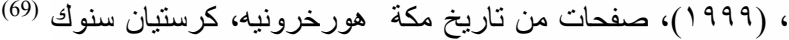

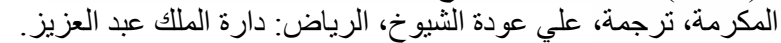

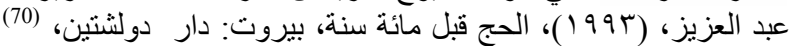
التقريب بين المذاهب الإسلامية. 
لكن للأسف هذه المحاولة الجريئة للأستاذ الانصاري لم تكلل في حينها بالتقليد والمحاكاة، كما حدث مع لـ كتابه " موسوعة تاربخ مدينة جدة" حيث عزفت أغلب الكتابات التي صدرت بعدها عن الاعتماد على التاريخ الشفوي إلا النزر القليل منها. وتأخر الاهتمام به إلى مرحلة متأخرة سنتطرق إلبها في السطور التالية. فدراسة الأستاذة فاطمة عبد العزيز الحميدان والمعنونة ب" مدينة جُدة - الموقع، البيئة، العمران، السكان" (VV)، و "النشاط التجاري لميناء جُدة - خلادله الحكم العثماني الثاني ד 91 (م"(VA) لمبارك محمد المعبدي، و "جُدة في مطلع القرن العشرين الهجري"(va) لنوال سراج ششه، و "جُدة خلال الفترة 1.9 ام، دراسة تاريخية وحضارية في المصادر المعاصرة"|(^) لصابرة مؤمن إسماعيل، و و "التجارة الخارجية لمدينة جُدة في العهد العثماني .ـ1 ام-

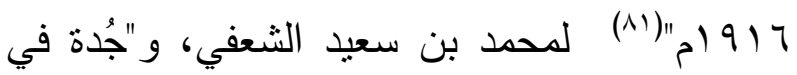

الانتظار على طوابير محطة التحلية القيمة و الوحيدة والتي كانت

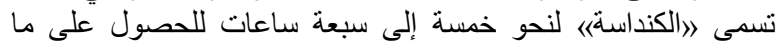
يحتاجون من مياه.

الحميدان، فاطمة عبد العزيز، ( • 99 (1)، مدينة جُة ـ الموقع، البيئة، (77)

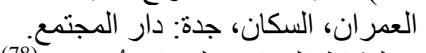

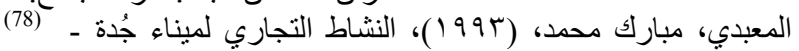

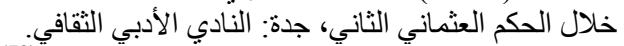

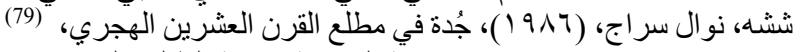
مكة المكرمة: مكتبة الطالب الجامعي.

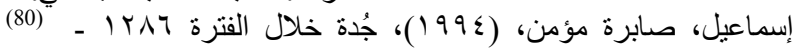

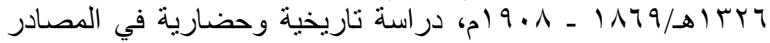

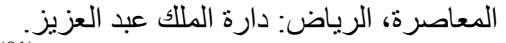

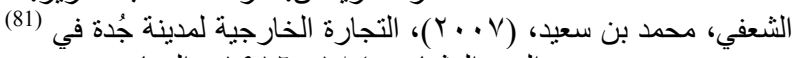

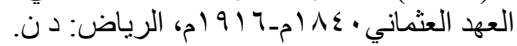

-كما أشرنا سابقا- لتأخر تخصيص مدينة جدة بكتب بحيالها في القرون الأولى ونظراً للنطور السريع الأي شهدته هذه المدينة خصوصاً في القرنين السالفين. لهذين السبيين جمعت العديد من الكتابات بين الاعتماد على الموثق المكتبي وبين الرواية الثفوية المتداولة، ولعل هذه الملاحظة تتطبق على أول عمل كبير وعميق حول المدينة وهو "موسوعة تاربخ مدينة جدة" للمؤرخ عبدالقدوس الأنصاري، الذي صدرت طبعته الأولى عام س79 ام وهو الكتاب الذي فتق -كما أشرنا سابقا- حاجز الكتابة والتذوين لتاريخ جدة وحاراتها ومجتمعها، فقد اعتمد الأستاذ الأنصاري في موسوعته على ما توفر لايه من كتب ووثائق ناريخية كما نهل العديد من مادة موسوعته من التراث الشفوي الذي كان يعايشه ويتحفظه عن آبائه وكبار المدينة، لذا من الممكن اعنبار هذه الموسوعة أول محاولة حديثة لدمج التاريخ الثفوي كمصدر لتاريخ جدة، إلا أن المحاولة الأهم والأبرز في هذا المضمار هي كتاب " تاريخ العين العزيزبة بجُدة"(Vo) للأستاذ الأنصاري نفسه والتي نشرها عام 979 (م، ووثق فيها تفاصيل نشأة العين العزيزية والتحولات الاجتماعية والاقتصادية التي فرضتها هذه العين على المجتمع الجداوي(VI)، معتمداً بشكل شبه محوري على المنقول الثفوي بين سكان المدينة.

الانصاري، عبد القدوس، (979 (19) ناريخ العين العزيزية بجُدة، جدة: (75)

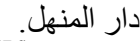

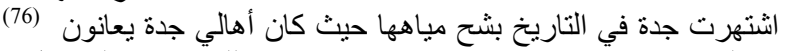

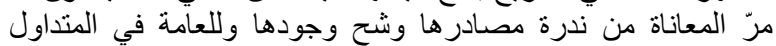

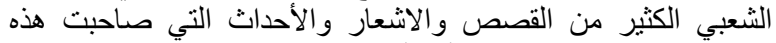

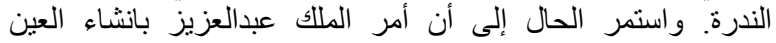

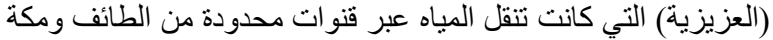

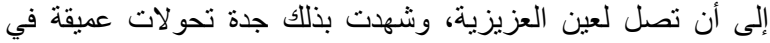

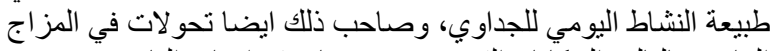

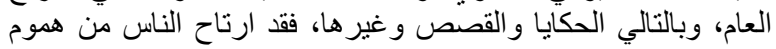


الرخاء والثدة"(^9) من تألبف خالد محمد باطرفي، وكتاب فيصل حسن البكري بعنوان "جدة.. تاريخ وحضارة"(·9)، بعد هذه المحاولات صدر العمل الأهم في مراحل تدوين التاريخ الثفوي للمدينة وهو كتاب "جُدة التاريخ والحياة الاجتماعية"(19) للأستاذ محمد لمدين وهن صادق دياب، وهو محاولة رائعة وثرية لتوثيق الحياة العامة والحياة العلمية والثقافية في جدة من خلال المتدوال الثفوي، حيث لم يعتمد المؤلف كثيرا على التاريخ المدون، ونزل بقلمه يكتب ويدون مأثثرات وحكايات الحياة العامة للمدينة وتفاصيلها بشكل مبدع جدا، هذا المنهج وظفه المؤلف مرة ثانية في

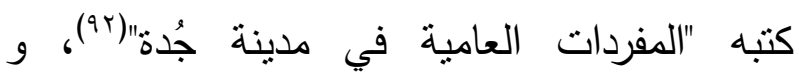

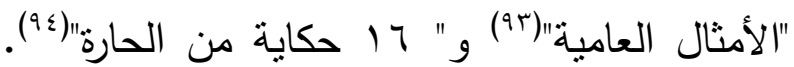
على منوال هذا العمل صدر كتاب " جُدة: حكاية

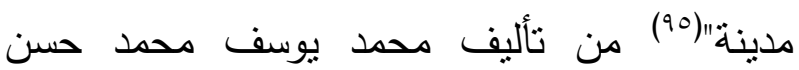
طرابلسي، وظّف فيه المصادر الثفوية والثعبية بشكل واضح وجلي، ووثقّ فيه مؤلفه للحياة العامة في جدة وتطور أنثكال الحياة فيها مستنداً بشكل وتئل كبير على المرويات الثفوية التي ورثها المؤلف وعاش حياته يسمعها في حارات جدة التي عاش

باطرفي، خالا محمد، (997 ( ))، جُدة أم الرخاء و الثدة، جدة: دار (89)

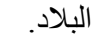

البكري، فيصل حسن، (T ( • (Y)، جدة تاريخ وحضارة، جدة: دار (90)

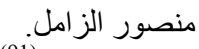

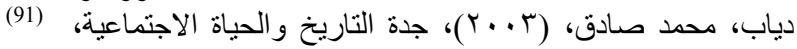
جدة: دار العلم.

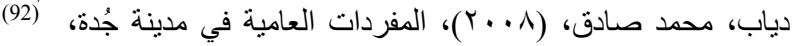

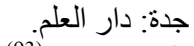

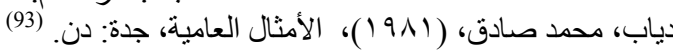

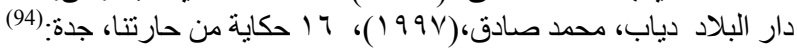

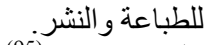

الطر ابلسي، محمد حسن، (7 . Y)، جدة: حكاية مدينة، الرياض: دن. (95)
العصر المملوكي"(ז) لسلوى عبدالقادر السليمان، و "جدة في التاريخ الحديث من $101 \mathrm{~V}$

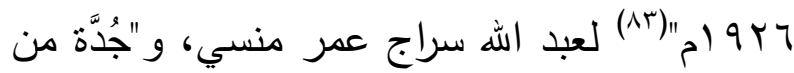

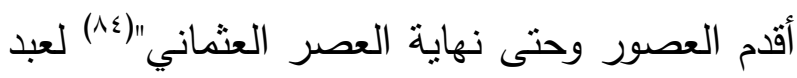

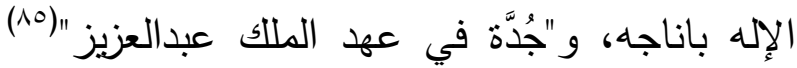

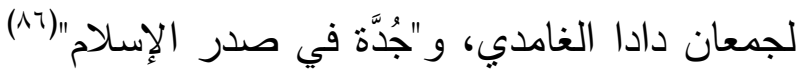

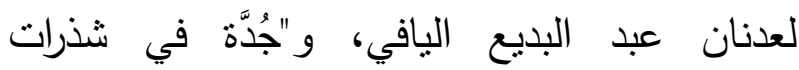
الغزاوي"(Av) للمؤلف نفسه، و "جدة صفحات لونات مشرقة من تاريخها العلمي والدعوي في القرن الرابع عشر هره

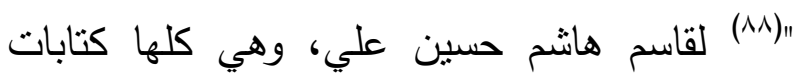
اعتمدت المنهج التاريخي التقليدي القائم على وهي المصادر والوثائق والمدونات التاريخية، وأهملت بشكل واضح المرويات الثفوية والمصادر الثنعبية كمصدر لها. بعد هذه المجموعة من الكتابات، ظهرت مجموعة

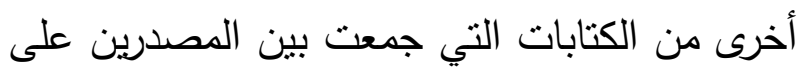

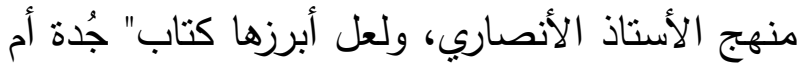

عبدالقادر، سلوى، (1. (Y)، جُدة في العصر المطلوكي، جدة: النادي (82)

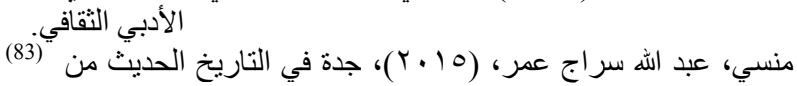

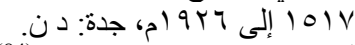

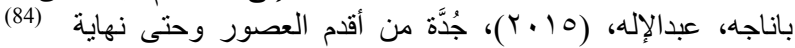

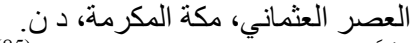

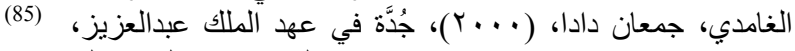

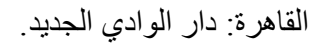

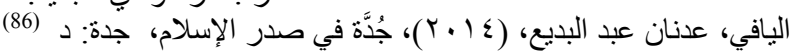

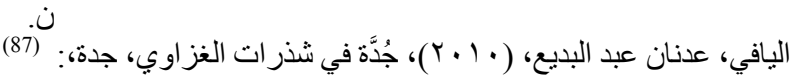
مطابع جريدة المدينة.

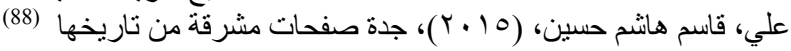
العلمي والدعوي في القرن الرابع عشر لقاسم هاشم حسين علي، جدة:

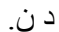


أكثر من أي مصدر آخر وتعددت الأعمال فيه بشكل كبير جداً، و من أبرز هذه الأعمال نذكر كتاب "شخصبات في جدة(r+()، والكتاب الثيق "جدة أم الرخاء والثدة، تحولات الحياة الأسرية بين

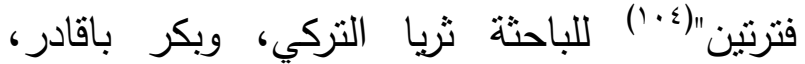
ومشاركة الباحثة آمال طنطاوي، وكتاب "الهجرة الريفية الحضرية :دراسة في تكيف المهاجرين إلى مدينة جدة"(0.1) لهدى العامودي، وأبو بكر باقادر والكتابين الأخيرين محاولة أنثرولوجية تحليلية معاصرة اعتمدت المنهج العلمي الصارم في التعامل مع المصادر الثفوية والمكتوبة، وتختلف كثيرا عن ما سبقها من الكتابات في ناحية اللغة وطبيعة السرد والتحليل، كما تجدر الإشنارة إلى كتاب "ذاكرة الزمن

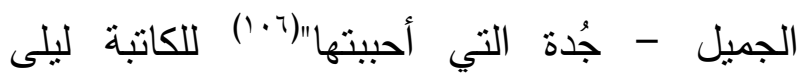
النعماني علي رضا، والمحاولة التوثيقة الرائعة لتاريخ إحدى أشهر أحياء جدة القديمة وهو كتاب" النزلة اليمانية - حي في ذاكرة جدة"(v•() من تأليف عباس بن محمد سعيد الفضلي ويمكن اعتبار هذا الكتاب

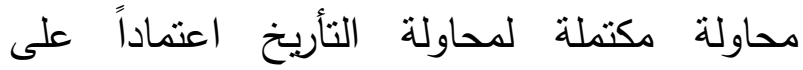
المصادر الثفوية، كما يبرز فيها هذا المضمار

\footnotetext{
التركي، ثريا، (99V ())، شخصيات في جُدة، جدة: الدار العربية (103) للعلاقات العامة و الخدمات.

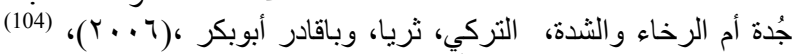

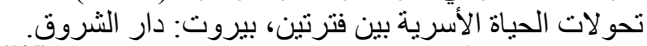

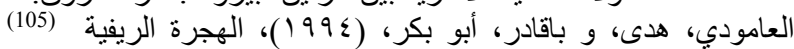

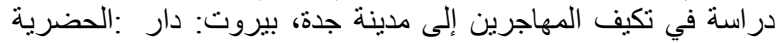
المنتخب العربي.

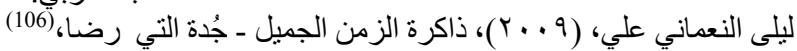

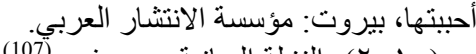

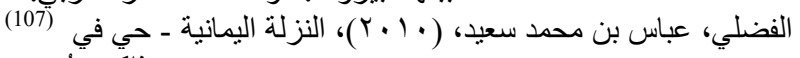
جدة: دن. ذاكرة جُدة،
}

فيها، والكتاب يمنت صفحة رائعة من أشكال التدوين للتاربخ الثفوي. تلى هذا العمل الرائع جملة كثيرة جداً من الكتابات التي اتسمت بمنهج الجمع بين المصادر الموثقة وبين المصادر الثفوية، وإن كان غلبت المصادر الثفوية على الكثير منها كما اعتمدت في أغلبها على المادة الخبرية التي وردت في كتاب محمد صادق دياب، كالمحاولة الرائعة للمهندس وهيب أحمد فاضل كابلي " الحرفيون في مدينة جدة"(דه")

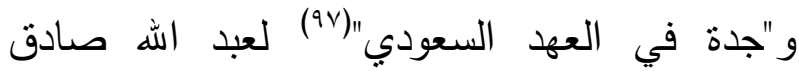

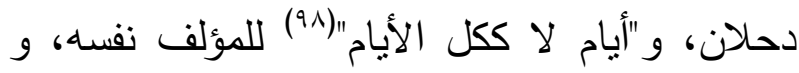
"حدث في جدة"(99) و "جدة معطيات المكان وأفاق

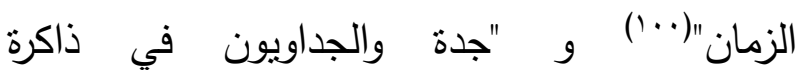
الانسان"(1.1) لعبد الرزاق أبو داود، و "الجدادودة

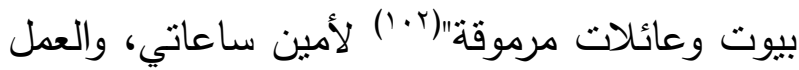
الضخم لعبد الله بن زاهر الثقفي والمعنون " العمارة بمدينة جدة في العصر العثماني 101V-7 19 |". بعد هذه الجملة من الكتابات برز نمط آخر في الكتابة معتمداً بشكل واضح على المصادر الثفوية

\footnotetext{
كابلي، وهيب أحمد فاضل، (ع . . ب)، " الحرفيون في مدينة جدة، (96)

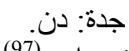

دحلان، عبد الله صادق، (10 ب ب)، جدة في العهد السعودي،جدة: دار (97)

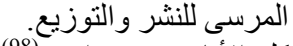

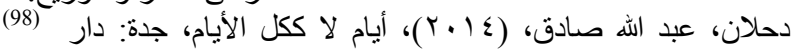

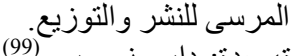

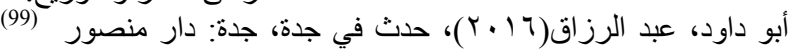
الز امل.

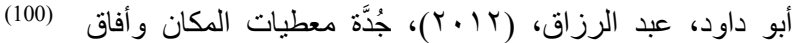

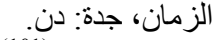

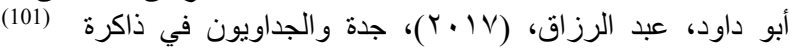

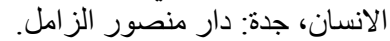

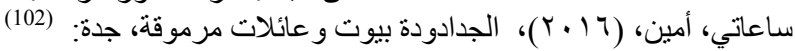
دن،
} 
أجدادنا قالوا"(1/1) لعمر أحمد مغربي، و " روي لي والدي وصحبه" لخالد صلاح سنوسي أبو

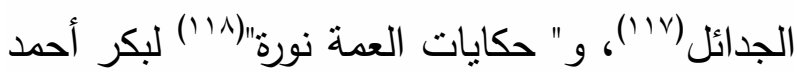
الحبشي" كأعمال رائدة في مسيرة تدوين التراث الثفوي للمدينة، إلا أنها كتابات اعتمدت المنهج السردي في مجملها، ولم تستتطق النص الثفوي وتستخرج مكنوناته الثقافية والنفسية، بخلاف كتابي " حكايات العطارين في جدة القديمة: دراسة تاريخية وصور اجتماعية للمعتقدات والوصفات الثعبية"(199) و "المعماريون في جدة القديمة"(rام) وللكاتب الصحفي عبد العزيز عمر أبو زبد، واللذين يعتبران من أهم الأعمال الرائدة التي يمكن اعتبارها مساهمة فارقة ونوعية في هذا المضمار ، وقد دشن المؤلف

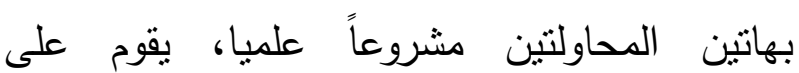
استتطاق المصادر الثفوبة والتراث الشعبي الجدّواي لرسم ملامح تطور القطاعات المهنية في حياتها العامة، في اعتماد شبه تام على "المصادر الحيوية" من العطارين والمعماربين القدماء، في التسجيل والتدوبن مع أصحاب الصنعة الأصليين، الذين لم يدركهم بعد قطار الموت، ولازالوا يتذكرون الكثير عن مهنتهم ونشاطاتهم، وقد جمع الكاتب مادة كتابه

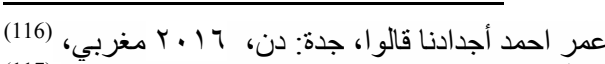

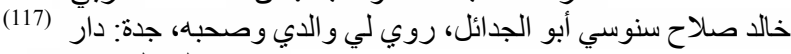

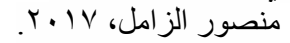

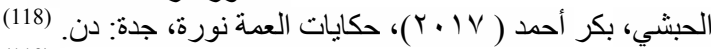

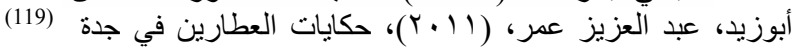

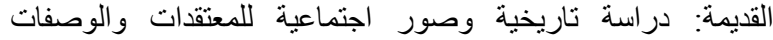
الثعبية، جدة: دار البلاد.

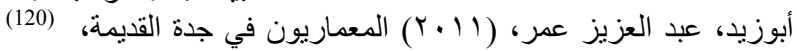
جدة: دار البلاد.
}

كتاب " جدة حكايات الزمن الجميل"(^•1) لمحمد درويش رقام. ولا يفوتتا أن نذكر محاولة عبد العزيز عمر أبوزيد في كتابه "الأسطورة في مدينة جدة"(9.") وهو كتاب جمع فيه كاتبه جملة من أساطير جدة من مصادرها الثفوية وقام بتحليلها والتعليق عليها، وكتاب" تاريخ عالم يؤرخ: جدة الإنسان والمكان"(·" لعبد الله مناع، وهو كتاب بعتبر مساهمة رائعة في توثيق المتذاول الثفوي لتاريخ المدينة، كما ييرز كتاب "حارة البحر موطن الأباء والأجداد"('1') لمحمد بن عبد الله بن هاشم النمر، وكتاب "حكتتي أمي في الناموسية حكاوي حلوة حجازية"(r') لعزيزة عبد الله محمد الصيرفي، و "حدث في بندر جدة"(III) لمحمد يوسف محمد حسن طرابلسي، و" حكايات شعبية قديمة من حارة الهنداوية بجدة"(أال) لصالح

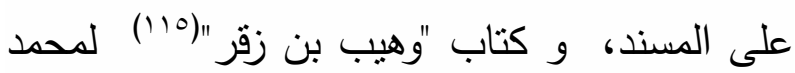
خالد باطرفي الذي اعتمد فيه منهجية ترجمة الأعلام ووثق فيه تطورات الحياة العامة في جدة من خلال اسهامات المرحوم وهيب بن زقر، وكذلك كتاب"

رقّام، محمد درويش، (10 + ب)، جدة حكايات الزمن الجميل، جدة: (108) سطور عربية.

أبوزيد، عبد العزيز عمر، (ד ا • ب)، الأسطورة في مدينة جدة، جدة: (109)

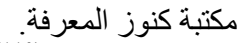

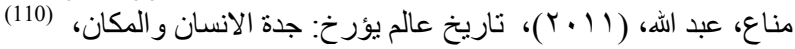

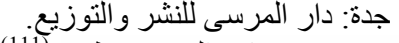

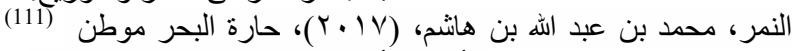

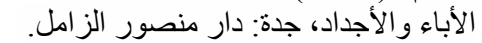

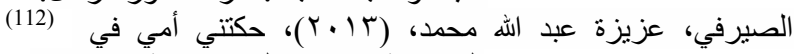

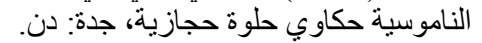

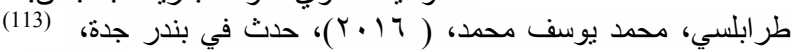
جدة: دن.

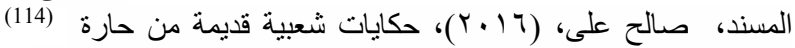

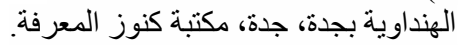

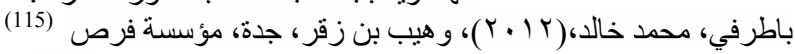
الحياة. 
يعد كتاب " أهل جدة ورحلة تعليم البنات"(؟r) لسمبرة بنت عباس حمزة شطا من المبادرات الذكية والرائعة في توثثق المرويات الثفوية على التحولات الثقافية والاجتماعية التي فرضها انتشار التعليم في مدينة

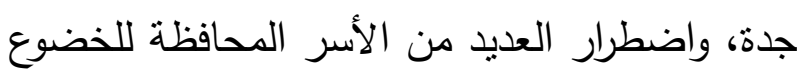

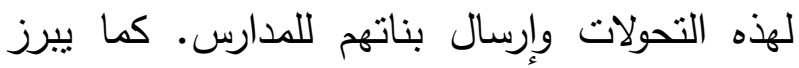
كتاب " تاريخ مدارس الفلاح والحاج محمد علي زينل، لحسين ضيدح البقمي، ككتاب يعتمد بشكل

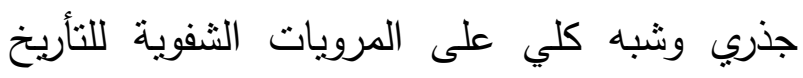
للموضوع الذي يتتاوله. بعد هذه المحاولة الرائعة ولا مشروع توثيقي واعد

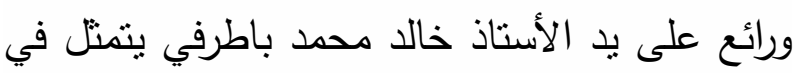

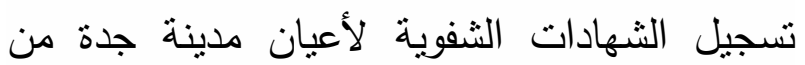

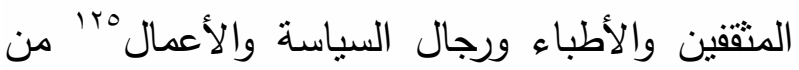
الذين واكبوا وعايشوا تطور المدينة وحياتها الثقافية والسياسية والاقتصادية في القرن العشرين، وهي ولطوري محاولة من الأهمية بمكان كونها ستحفظ تقاصيل

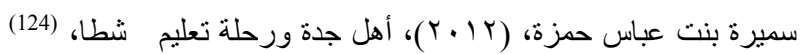
البنات، جدة: دن.

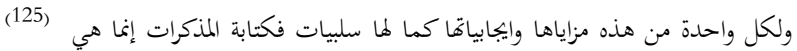

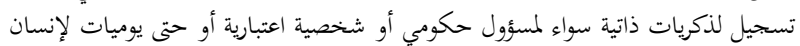

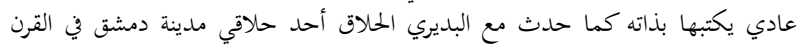

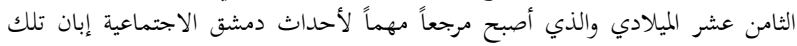
الفترة.
عبر لقاءات مطولة استمرت قرابة ثلاثة أعوام جلس

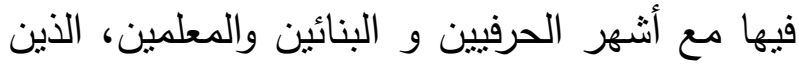
ساهموا في صناعة التميز العمراني للمدينة، فمن خلال هذه المحاولة المبدعة والاستثنائية حفظت لنا شهادات بنائين ونجارين وحرفين قدامى كبار ، أمثال: حسن محول وعيسى معتوق عبد العاطي، وإسماعيل عبد العاطي ومصطفى عبد الدايم، وعبد الله محمود

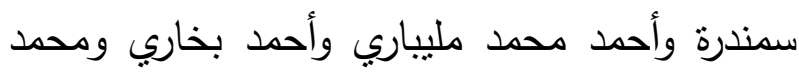
محمد زاكر. (Ir) وفي كتابه الأول تمكن المؤلف من إنقاذ أسرار مهنة العطارة من الاندثار عبر توثيق تفاصيل هذه المهنة التي كانت أحدى أنشط المهن وأهمها في المدينة عن طريق كتابة ذكريات العطارين القدامى، وتوثيق عبادات جدة القديمة، وتسجيل تفاصيل العلاقات المهنية بين العطارين والدايات وباقي المهن الثانية وفصّل حتى الوصفات التي كانت تستعمل في الاستطباب في القرون السابقة، وغيرها من التفاصيل

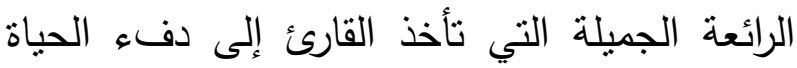

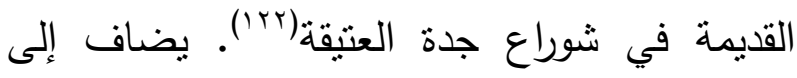
هذين العملين المميزين كتاب " التعليم الأهلي للبنين

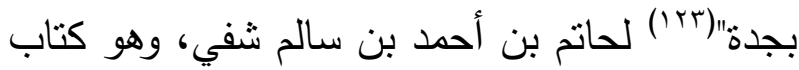
يوثق لنطور النظام التعليمي الحديث في جدة من خلال روايات رواد قطاع التعليم ورعاته الأوئل، كما لنطي

\footnotetext{
أبوزيد، عبد العزيز عمر، حكايات العطارين في جدة القديمة، ص، (121) ए纟

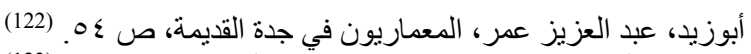

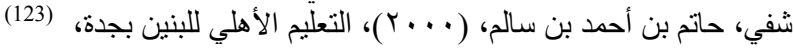

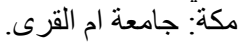


التعريف بشخصية الخواجة بني باللغة للقراء باللغة الإنجليزية من خلال ما جمعته عن حياته من روايات شفوبة لمن صاحبه وعايشه(rrr(T). لم يغب الأدباء عن جهود توثيق التراث الثفوي لجدة عن طريق تضمينه في أعمالهم الأدبية والفنية حفظاً

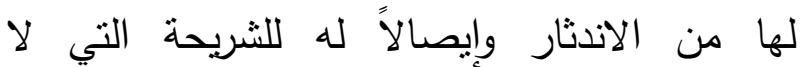
تستهوبها كتب التاريخ، وتبرز في هذا المضمار

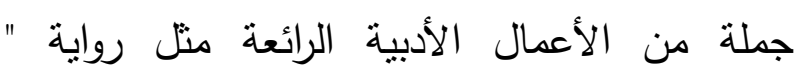

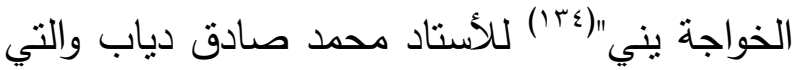
يؤرخ فيها بأسلوب أدبي راق لتاريخ مستوطن يوناني مسيحي لمدينة جدة وتفاصيل تفاعله مع الحياة العامة وسكان جدة ويؤرخ فيها لحالة التسامح التي كانت سائدة في تلك السنوات. كما صدر لله ديوان "مقام حجاز "(roro) الذي ضمن فيه المؤلف الكثير من تراثيات وأدبيات المجتمع الجداوي، ويمكن إيراد أمنتة عديدة من باب المثل لا الحصر على منل هذه

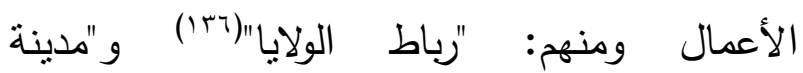
اليسر"(rrvir). لهند باغفار التي لها إسهامات عميقة جداً في نوثيق الفنون الثعبية والتراث المحكي في الحجاز ، وفي جدة بالخصوص، و "سور جُدة"(^rا)

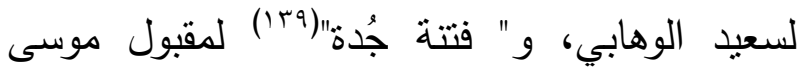

(133) See: Al-Khawaja Yanni (Yanni the Westerner): An Example of Muslim-Christian Tolerance in Jeddah during the 20th Century, Academic Journal of Interdisciplinary Studies, Vol 6, No 2. 2017.

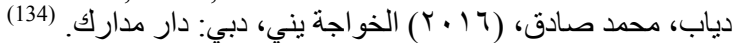

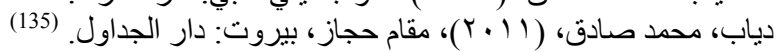

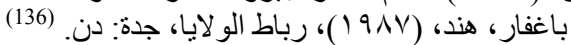

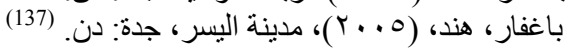

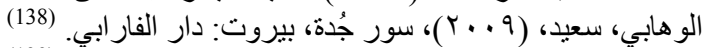

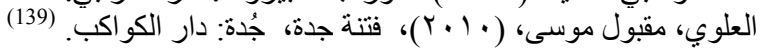

التاريخ الحديث من أفواه صناع أحداثه والمؤثرين فيه، وقد صدر حتى كتابة سطور هذه الدراسة عدد لابأس به من هذه السلسلة نورد منها كتاب "أحمد فئه

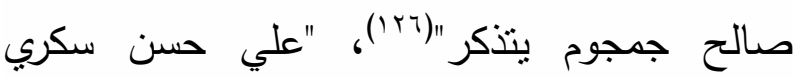

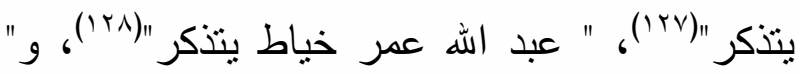

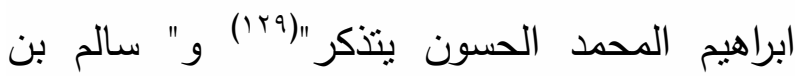

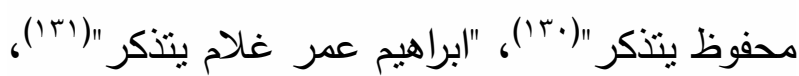
و "عبد الله الخزرجي يتذكر "(r"ا'). على أن هذا الكم المتتامي من الاهتمام بتاريخ جدة لهند

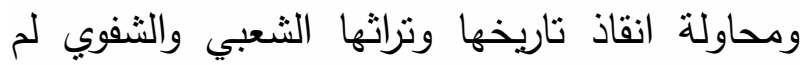
يتوقف، حيث لا زالت أعمال جليلة أخرى في طور الكتابة والإعداد للنشر، مثل: موسوعة أعلام مدينة جدة لقاسم هثام حسين علي، التي نرجم فيها لما

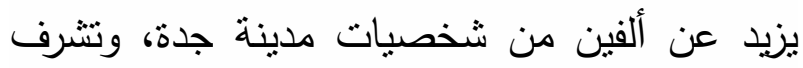

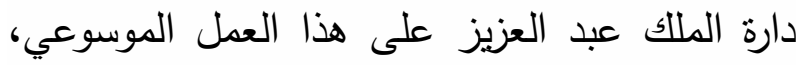
كما أن للاكتورة أميرة مصطفى كتاب في طور

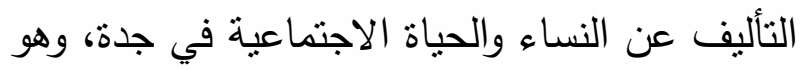
أول كتاب يخص تاريخ المرأة الجداوية بالتأليف والتوثيق، كما ساهمت الدكتور حسنة الغامدي في لي التحاه

باطرفي، خالد محمد، (ع ا ب r) أحمد صالح جمجوم يتذكر، جدة: (126)

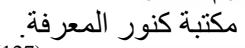

باطرفي، خالد محمد، (ع ( • Y)، علي حسن سكري يتذكر ، جدة: (127)

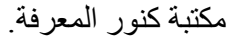

باطرفي، خالد محمد، (ع ا • ץ)، عمر خياط يتذكر ، جدة: مكتبة كنور (128)

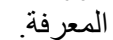

باطرفي، خالد محمد،(ع ا • Y)، ابر اهيم المحمد الحسون يتذكر، جدة: (129)

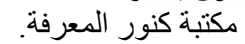

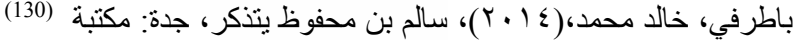

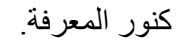

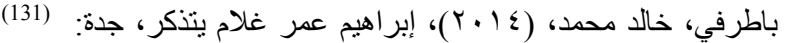
مكتبة كنور المعرفة فئذكة

باطرفي، خالا محمد، (ع ( ا ب)، عبد الله الخزرجي يتذكر، جدة: (132)

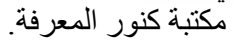


الاندثار، ونورد هنا جملة من الملاحظات على هذه

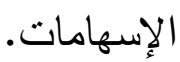

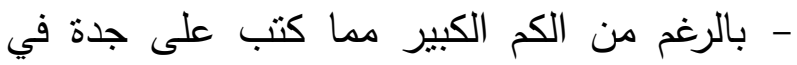
فتزة العقدين الأخيرين، وتزايد وتيرة الاهتمام بتاريخها بشكل ملحوظ في الآونة الأخيرة إلا أن تاريخ المدينة

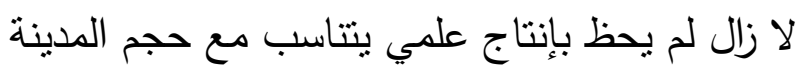
ودورها الحضاري على المستويين المحلي والعالمي، سواء من ناحية التأريخ لكافة جوانب الحياة فيها وإبراز المخزون الثقافي والسياسي والروحي فيها أو لون من حيث التسلسل الزمني للأحداث وفق التحقيب الزمني المعهود والمعروف. إذا لا زالت الكثير من الجوانب الثرية في حياة المدينة لم تحظ ولو بالنزر

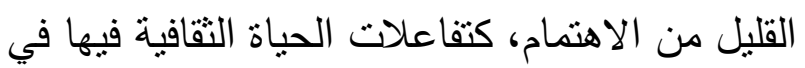
القرون الثلاثة الأخيرة، والتجاذبات التي فرضتها التيارات الفكرية التي مرت على المدينة، والحياة الروحية العرفانية التي يبدوا أنها كانت ثرية جداً في

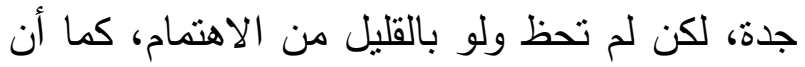

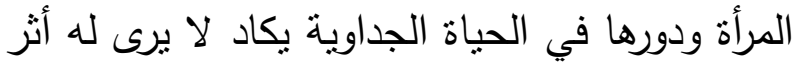
إلا في القليل النادر، ولم تخصص المرأة بكتابات

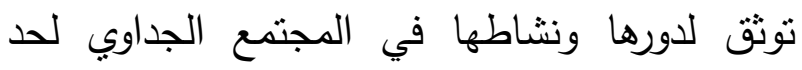
كتابة هذه السطور، كما أن إيفاء التسلسل الزمني

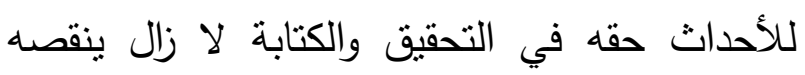
الكثير من الاهتمام، إذا لا زالت هناك ثخرات عديدة

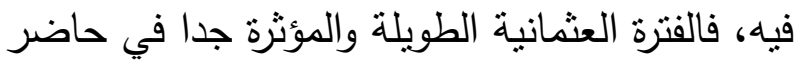
جدة لم تحظ بحقها من الكتابة، كما لم تفرد الفترة
العلوي، و" البازان وسيل البغدادية"(•؛) ليحيى

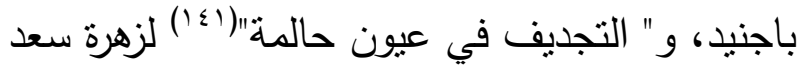

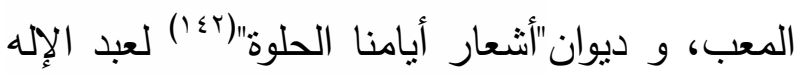

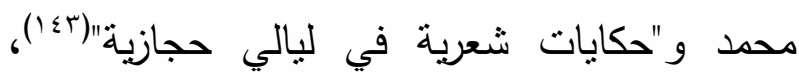

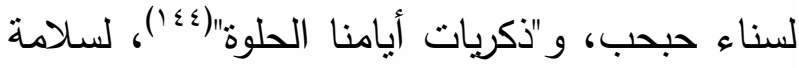

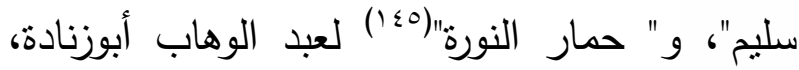

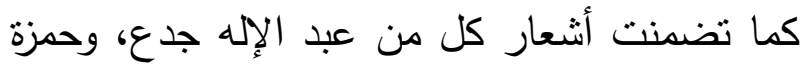

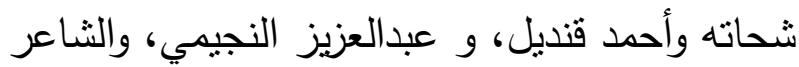
الثعبي الثهير عبد الله دبلول الكثير من تفاصيل الحياة العامة والمرويات والأمثلة الثعبية والمقولات الثفوية التي لا زالت متداولة في المجتمع الجدّاوي. ت- تقييم تدوين التاريخ الثفوي لجدة لان يتضح من السرد السابق أن الاهتمام بالتأريخ لجدة لهندان اكتسب وتيرة متزايدة منذ منتصف القرن العشرين

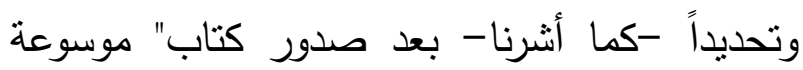
تاريخ مدينة جدة"، التي ألهمت قرائح المؤرخين من لنابن

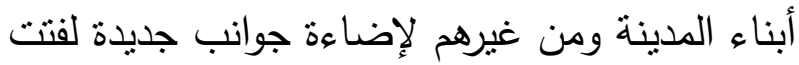
الموسوعة انتباهم إليها، وبالموازاة مع هذا التزايد

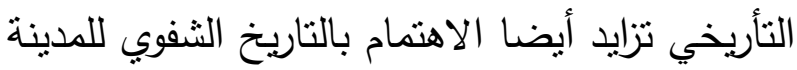
وبرزت العديد من المحاولات لتدوينه وإنقاذه من لن

يحيى، (•(Y. (Y)، البازان وسيل البغدادية، جدة: دار باجني، (140) الحضارة:

المعب، زهرة سعد، (د ت) التجديف في عيون حالمة، جدة: دار (141) العلم.

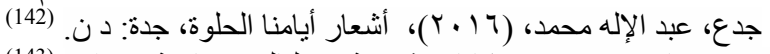

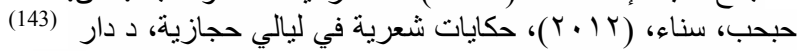

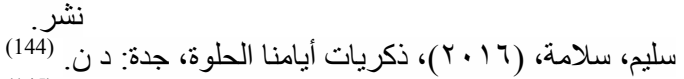

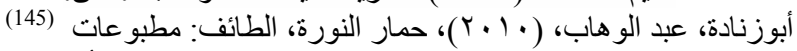
نادي الطائف الأدبي . 
لم تلتزم بخطوات تجميع المادة التاريخية الخبرية

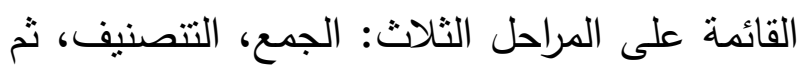
التحليل، كذا وآليات الجمع القائمة على طرق ثلاث

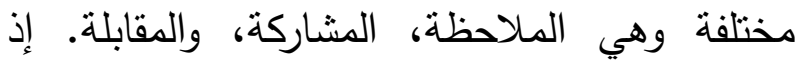
الملاحظ أن أغلب المحاولات السابقة اعتمدت مرحلة واحدة من هذه المراحل، دون أن تمرر المادة المجموعة وفق المنهجية المنضبطة التأريخية، لذا لهرن تتشابهت أغلب الكتب في محتوياتها، وقلّ الجديد والفردي في العديد منها، وغابت المقارنة والتحليل والنقد بشكل واضح نماماً. - بالرغم من التزايد الواضح لحجم تدوين التاريخ

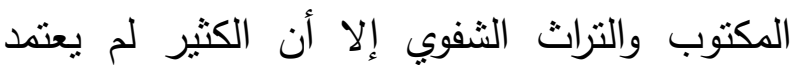
المنهج العلمي في الكتابة التاريخية سواءً تعلق الأمر بمنهجية التاريخ المكتوب أو التاريخ الثفوي، حيث تمتزج في الكثير منها أمزجة في الكتابة التاريخية تعتمد كل منها منهجيات مختلفة. إذ يقفز الكثير من مؤلفي الكتب المتداولة بين روح كتابة المذكرات واليوميات التي تتميز بمنهجية انسيابية ذاتية غير منضبطة، وبين روح التسجيل للأحداث والمشاهدات، وتدوين الحكايا الثعبية المتداولة التي تحتاج أيضاً إلى منهجية مختلفة عن سابقته، وفي أحبان أخرى يوظف بعضهم المنهج التاريخي الرصين في بعض إنى جزئيات كتابه. هذه الهلامية المنهجية أثرت بشكل واضح على جدية بعض الأعمال المنشورة، وعلى هلى لهاه القيمة العلمية لها. ولعل صدور أغلب هذه الكتب عن كتّاب ليسوا مشتغلين بالحقل التاريخي الأكاديمي
المملوكية إلا بكتاب أو كتابين لا يغطيان ثراء الفترة التاريخية وتطور حياة جدة أثناءها. - تطغى الصبغة الثمولية على أغلب الكتب المنشورة عن تاريخ جدة سواءً تلك التي تعتمد الوثائق التاريخية أو التاريخ الثفوي، حيث بحاول أغلبها الحديث عن كل جوانب الحياة دون تخصيص جوانب محددة دون غيرها، نأثراً من كتابها بمنهجية

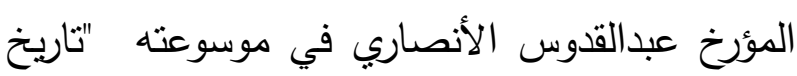
مدينة جدة" التي اتبع فيها الطريقة الثمولية والكلاسيكية في طرح المادة العلمبة. ولعل الاستثناء البارز في هذا المضمار هو محاولة الكاتب عبد العزيز عمر أبو زيد في كتابيه " حكايات العطارين هوان هابه في جدة القديمة: دراسة تاريخية وصور اجتماعية للمعتقدات، والوصفات الثعبية" و "المعماريون في لي

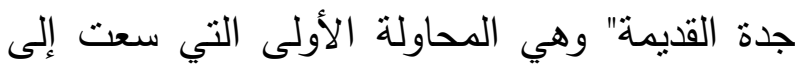
الابتعاد عن الثمولية التي صبغت أغلب الأعمال السابقة لها. - يتضح من مطالعة الأعمال المنشورة والتي عملت على توثيق التراث الثفوي والثعبي أن عدداً قليلا من الكتاب كتب عما عاصره وما عايشه من أحداث، وأن أغلب ما كتبوه هو من ما سمعوه من معمري المدينة أو الكبار من أهلهم، لذا فإن الكثير مما كتب لم يكن يعرفه غيره، وهو ما يضيف قيمة علمية إضافية لبعض هذه الأعمال، إلا أن إثكالية

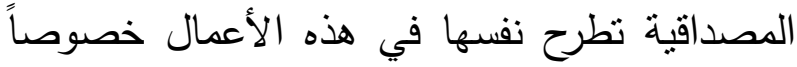
أن أغلب الكتب التي اعتمدت تدوين التاريخ الثفوي 
تحولات الحياة الأسربة بين فترتين" الذي اشترك في تأليفه كل من ثريا التركي، وبكر باقادر وآمال طنطاوي، وكتاب "الهجرة الريفية الحضرية :دراسة

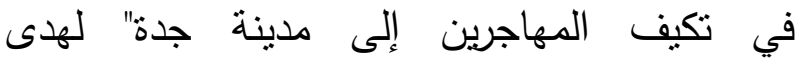
العامودي، وأبو بكر باقادر، وهما محاولتان فريدتان في محاولة نتزيل المناهج التاريخية و الأنثروبولوجية الحديثة في تحليل النصوص الثفوية المتداولة عن تاريخ جدة، ويمكن من خلال تصفح العملين الوقوف بوضوح على التباين المنهجي بينهما وبين غيرها مما كتب عن المدينة. - تبرز إثكالية مصدرية عميقة في متابعة وحصر الروايات الثفوبة لمدينة جدة بالذات، تتعلق بالتجاذبات القائمة بين مكونات المجتمع الجداوي من حضر وبدو وعوائل عريقة، وأخرى جديدة على المدينة ومحاولة بعض الرواة اثبات عراقة عائلته في المدينة ولو بلوي الروايات أو نقل قصص وبطولات ضعيفة، تتسب شيئا من الفضل لأجداده وعائلته، وهو الأمر يوقع الباحث المتمص في مطبات على غاية كبيرة جدا من الصعوبة، خصوصاً في المجتمع السعودي المعروف بترابطه الاجتماعي وحسه العائلي القوي والمتوقد.

- من خلا تقحص التسجيلات الصوتية التي سجلتها دارة الملك عبد العزيز لمجموعة كبيرة من أعيان مدينة جدة، يتضح أن الكثير من هذه التسجيلات ليست بالسهولة التي تساهم في تيسير عمل الباحثين والمؤرخين، حيث لاحظنا أن الكثير
كالصحافيين والفنانين والمحامين والتجار، كان لله دور في حالة اللانضباط المنهجي التي اكتست بها العديد من الكتابات الحديثة عن جدة. - بناءً على الملاحظة السالفة يمكننا القول إن الأعمال الأهم التي طبعت عن تاربخ جدة والتي اعتمدت على مصادر التاربخ الثفوي لم تتج من الإنشكال المنهجي السابق، فتى المؤرخ الكبير عبدالقدوس الأنصاري في كتابه "موسوعة تاريخ مدينة جدة" لم يتحر الفصل بين منهجيات الكتابة في المحاور الثلاثة التي أوردناها سالفا، حيث جاءت الكثير من فصول الموسوعة كتدوين وتسجيل لأحداث ووصف لواقع عايثه المؤلف، كما أهمل المنهج التاريخي حتى في الفصول التي كانت تتطلب صرامة منهجية كالقصول التي تحدث فيها عن قدم مدينة جدة والبراهين التاريخية عن أول من سكنها وعمّرها. والأمر نفسه بنطبق على العمل الذي يليه في الأهمية وهو في هذا المضمار وهو كتاب "جدة التاريخ والحياة الاجتماعية" للراحل محمد صادق دياب، فعلى الرغم من مكانة المؤلف وقيمة كتابه وأثزه العميق في الكتابة عن تاريخ جدة، إلا أن الكثير من فصول الكتاب لم تخضع لشروط ومنهجية الكتابة التاريخية، أو منهجية تدوين التاريخ الثفوي. والماحظة نفسها تتطبق عن ما كتبه كتبة المؤرخ محمد رقام وغيره واللافت للانتباه أن المحاولات الجادة لتفادي هذا الإشكال لم تحظى بما تستحق من الاهنمام والتداول، ككتاب "جدة أم الرخاء والثدة: 
وتستجلب فيها معاول النقد والتحليل لكل ما يتداول من روايات وقصص تحكي ثثايا التاريخ والأحداث في المدينة. وبالرغم من العدد القليل لمحاولات تدوين التاريخ الشفوي إلى ولى لهائ

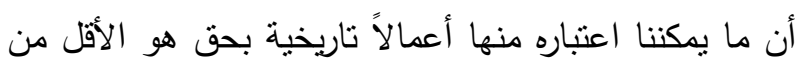
القليل نظراً للطابع الحكواتي الذي صدرت فيها العديد من هذه اعنه

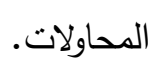

من هذا المنطلق تبقى جدة وشوارعها وحواريها كالتمثال الجميل الذي لايزال يحتاج لمن يشذب تهن تهاصيله ويبرز ملامحه الفاتتة والتي لاتبدو للرائين من بعيد. لآيرال

\section{المصادر والمراجع العربية}

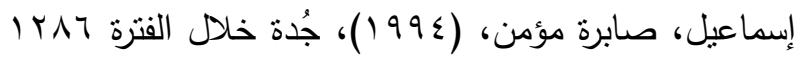

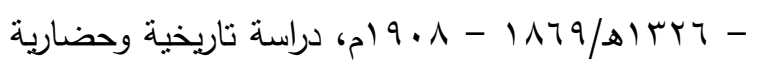
في المصادر المعاصرة، الرياض: دارة الملك عبد العزيز. الانصاري، عبد القدوس، (979 (19) تاريخ العين العزيزية دارة العادية

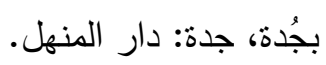

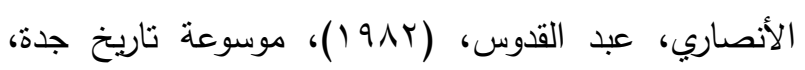
القاهرة، دار مصر للطباعة.

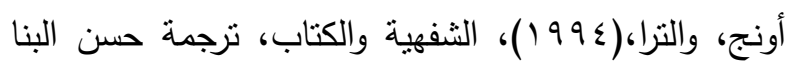

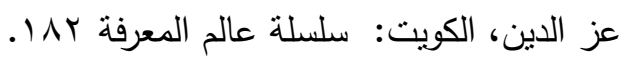

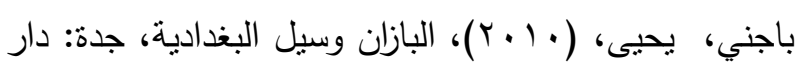
الحضارة.

باطرفي، خالد محمد، (997 (1))، جُدة أم الرخاء والثدة، جدة:

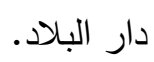

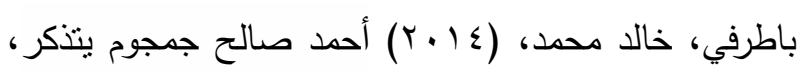

$$
\text { جدة: مكتبة كنور المعرفة. }
$$

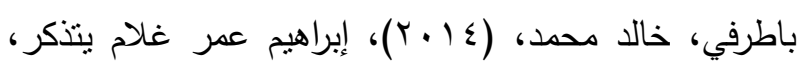

$$
\text { جدة: مكتبة كنور المعرفة. }
$$

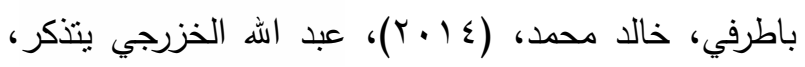

$$
\text { جدة: مكتبة كنور المعرفة. }
$$

من التسجيلات لم تكن ممنهجة وفق تبوبب موضوعي، يمكّن الباحث من العثور السهل على مراده من المادة الخبرية المسجلة، إذ يضطر الباحث في بعض الأحيان لسماع عدة ساعات من من مأ التسجيلات لتوثيق معلومة واحدة، وفي بعض الت بلت الأحيان لا يعثر عليها بعد كل الجهد الذي بذله، وذللك لغياب تبويب واضح للمواضيع العامة في التاربخ

\section{الخاتمة}

بالرغم مما قيل وما كتب عن عروس البحر الأحمر من كتب وأعمال علمية تخلد عراقتها وثراء أيامها وحاراتها، فيما بين القرنين التاسع عشر و الحادي والعشرين إلا أن حجم ما كتب وهن ومنهجيته لا زالت لا ترقى لقيمة هذه المدينة ولتهينة ودورها الحضاري الكبير الذي لعبته منذ اللحظات الأولى لعودتها

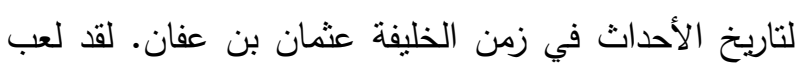
تأخر تدوين تاريخ مدينة جدة دوراً بالغاً في إدراج الكثير من فن فين

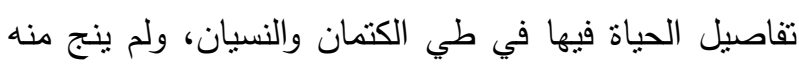
إلا ما تداولته الألسن ودونته الأقلام، وهو حتماً أقل من القليل

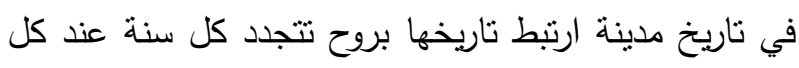

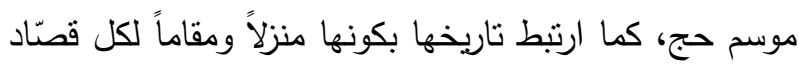
بيت الله من العلماء والمؤرخين والسياسيين الذين كانوا يفدون إليها كل سنة لأداء فريضة الحج. لهن. إن المحاولات المتزايدة لاستدراك النقص التأريخي للمدينة

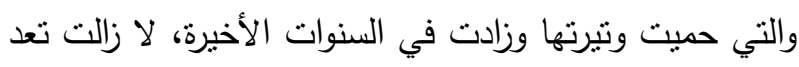
محاولات تأسيسية مادام لم تصهر كلها في أعمال موسوعية ضخمة تجتمع فيها كل الجهود الأكاديمية والرموز الاجتماعية، في نشاط منهجي موسوعي كالذي نولاه الدكتور سعد الصويان عن نوثثقة للتراث الثعبي في المملكة العربية السعودية، يعتمد فيها على المنهجية التاريخية الرصينة 
حبحب، سناء، (Y (Y. (Y)، حكايات شعرية في ليالي حجازية،

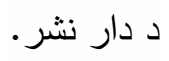

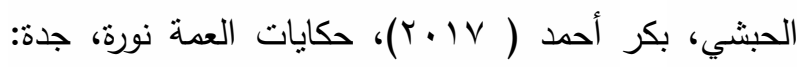
دن.

حبيدة، محمد، (ع · ㄷ)، التاريخ الثفهي، من أجل تاريخ إثكالي: ترجمات مختارة، طا، منشورات كلية الآداب

\section{والعلوم الإنسانية القنيطرة}

حبيدة، محمد، (ץ/ (ץ)، التاريخ الثفهي، كتابة التاريخ: قراءات وتأويلات، طا، الرباط: دار أبي رقراق للطباعة

$$
\text { والنشر - ماءر }
$$

الحربي، ملفي، رئيس هيئة السياحة يؤكد اهتمام خادم

الحرمين بقضية التراث الوطني ، جريدة الرياض، 03

$$
\text { ديسمبر } 10
$$

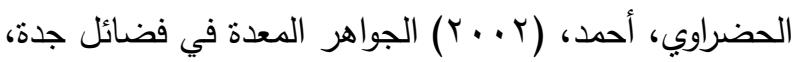

القاهرة : مكتبة الثقافة الدينية.

خالد صلاح سنوسي أبو الجدائل، روي لي والدي وصحبه،

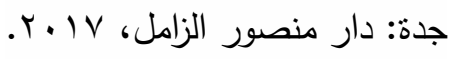

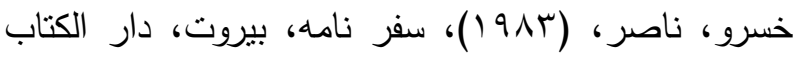
الجديد.

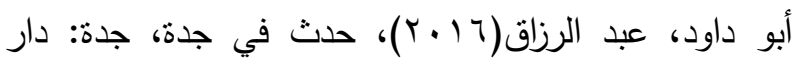
منصور الزامل.

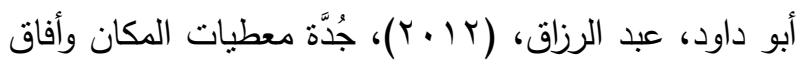

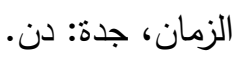

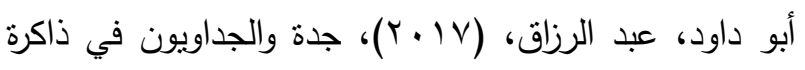
الانسان، جدة: دار منصور الزامل.

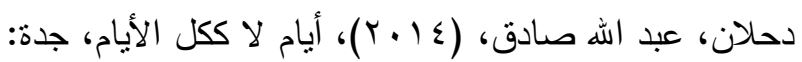
دار المرسى للنشر والتوزيع.

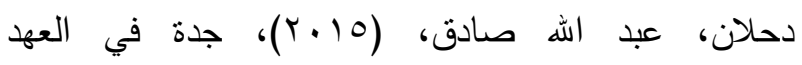
السعودي،جدة: دار المرسى للنشر والتوزيع.

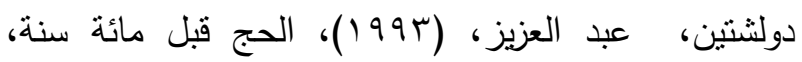
بيروت: دار التقريب بين المذاهب الإسلامية.
باطرفي، خالد محمد، (؟ ا. Y)، علي حسن سكري يتذكر، جدة: مكتبة كنور المعرفة.

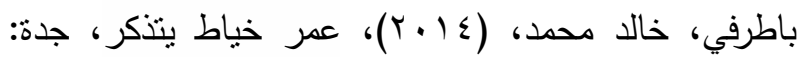
مكتبة كنور المعرفة. باطرفي، خالد محمد،(ع (ب)، ابراهيم المحمد الحسون يتذكر ، جدة: مكتبة كنور المعرفة.

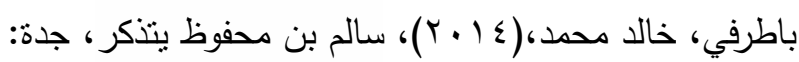
مكتبة كنور المعرفة.

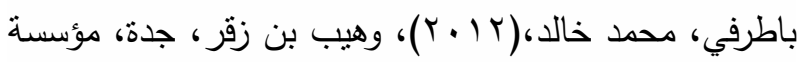

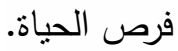

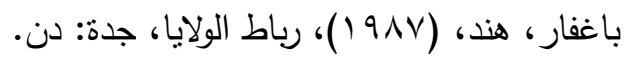

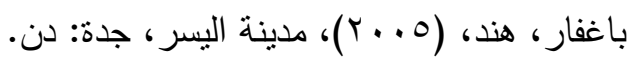

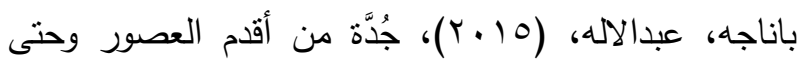
نهاية العصر العثماني، مكة المكرمة، د ن.

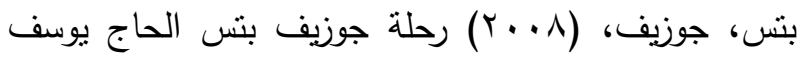
الى مصر ومكة المكرمة والمدينة المنورة، ترجمة ودراسة: عبد الرحمن عبداله الثيخ، القاهرة: الهيئة المصرية العامة للكتاب. ابن بطوطة، (1991)، تحفة النظار في غرائب الأمصار وعجائب الأسفار، طنجة، المغرب: مدرسة الملك الك السعدي.

بيرنون، رنشارد، ( • ( • (ب)، رحلة بيرتون الى مصر والحجاز ، ترجمة وتعليق: عبد الرحمن عبداله الثيخ، القاهرة: الهيئة

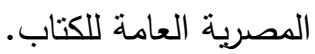

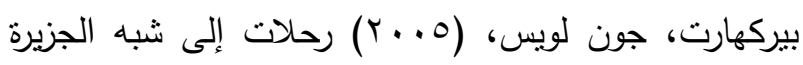
العربية، ترجمة هتاف عبد الله، بيروت: مؤسسة الانتشار العربي.

ابن جبير، محمد بن أحمد، (917) (1917، رحلة ابن جبير،

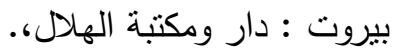

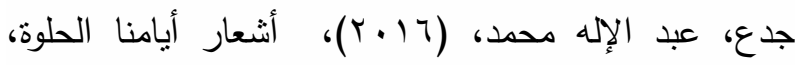


ساعاتي، أمين، (T/ (Y)، الجدادودة بيوت وعائلات

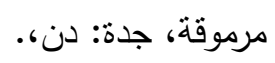

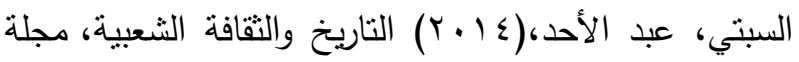

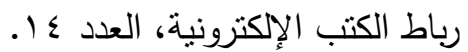

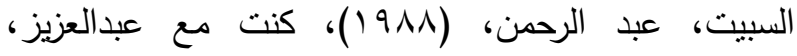

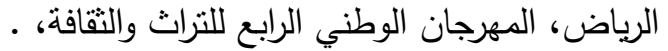

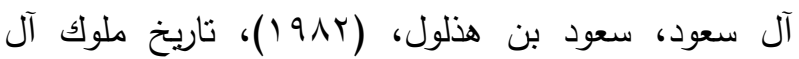
سعود، الرياض: مطابع المدينة.

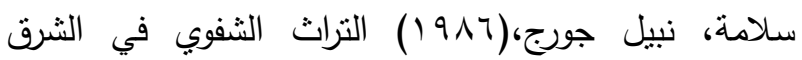
الأدنى ومنهجية حمايته، دمشق : وزارة الثقافة السورية.

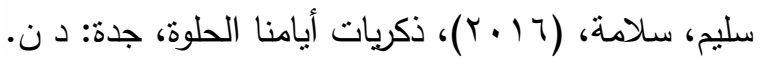

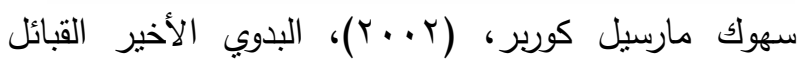

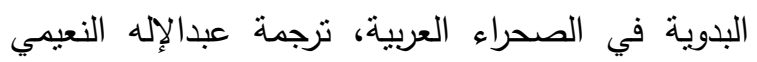

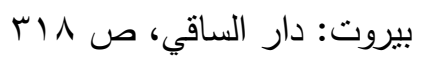

ششه، نوال سراج، (9191)، جُدة في مطلع القرن العشرين الهجري، مكة المكرمة: مكتبة الطالب الجامعي.

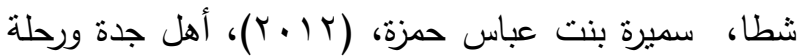

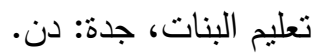

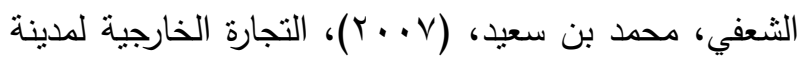

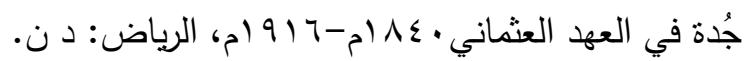

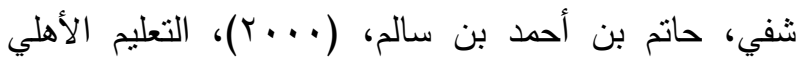
للبنين بجدة، مكة: جامعة ام القرى.

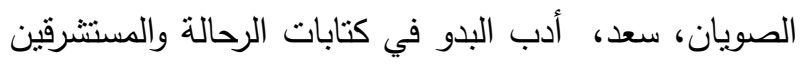

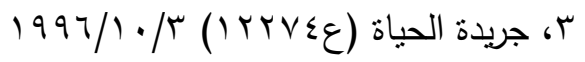

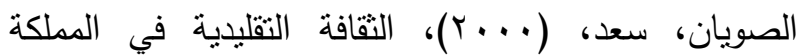
العربية السعودية، دار الدائرة للنشر و التوثيق. التهان.

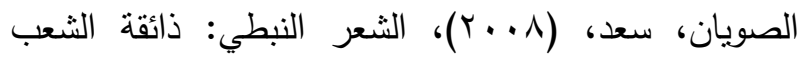
وسلطة النص، الرياض: الأنساق للنشر والتوزيع.

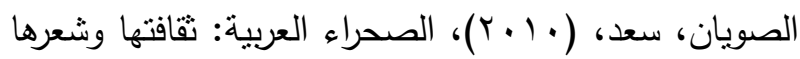
عبر العصورز قراءة انثروبولوجية، بيروت : الثبكة الثة الثراء

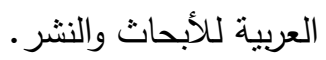

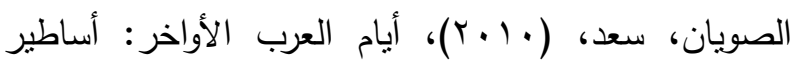

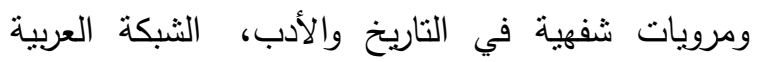

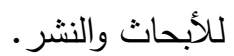

دي فارثيما، لود فيغو، (ع991)، الحاج يونس المصري:

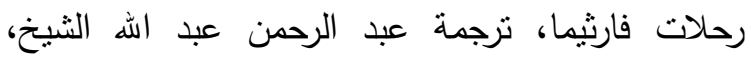

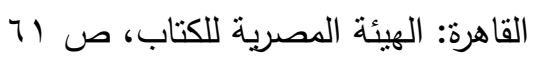

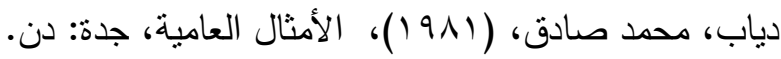

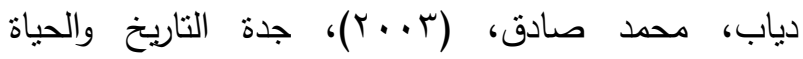
الاجتماعية، جدة: دار العلم.

دياب، محمد صادق، (^ . . ץ)، المفردات العامية في مدينة

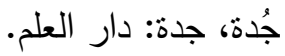

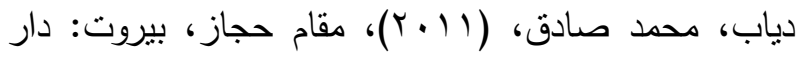

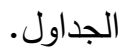

دياب، محمد صادق، (T (Y) الخواجة يني، دبي: دار مدارك. دياب، محمد صادق،(1997)، 17 (197اءية من حارتنا، جدة: دار البلاد للطباعة والنشر •

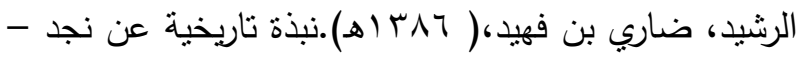

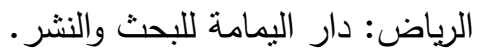

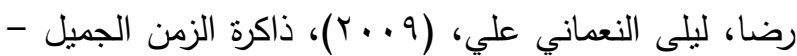
جُدة التي أحبيتها، بيروت: مؤسسة الانتشار العربي.

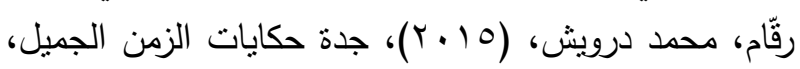
جدة: سطور عربية.

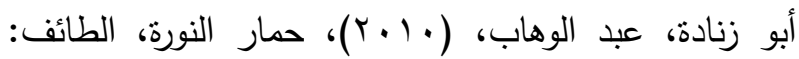

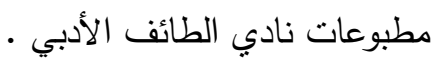

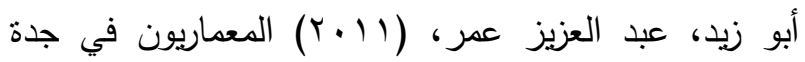
القديمة، جدة: دار البلاد.

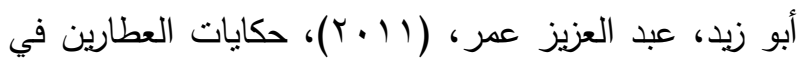
جدة القديمة: دراسة تاريخية وصور اجتماعية للمعتقدات والوصفات الشعبية، جدة: دار البلاد.

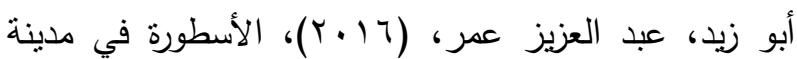
جدة، جدة: مكتبة كنوز المعرفة.

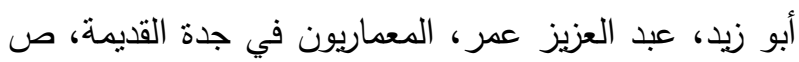
.0 أبو زيد، عبد العزيز عمر، حكايات العطارين في جدة

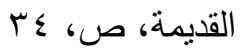


كابلي، وهيب أحمد فاضل، (ع . . Y)، " الحرفيون في مدينة

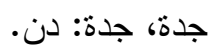

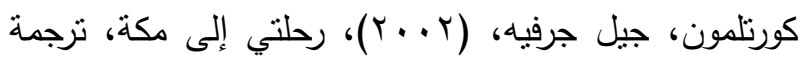
محمد احمد الحناش، الرياض: دار التراث.

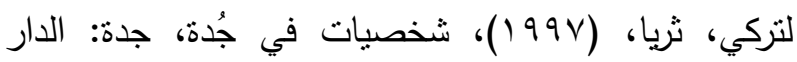

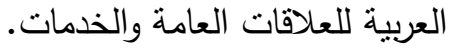

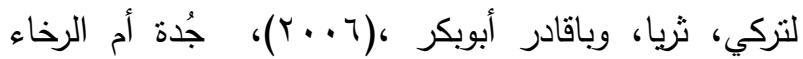

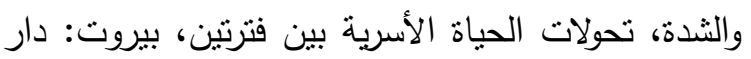

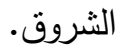

لحميدان، فاطمة عبد العزيز، (99 (19)، مدينة جُدة -

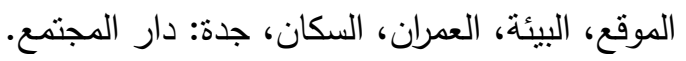

ابن المجاور، يوسف ابن يعقوب، (997)، تاريخ المستبصر ، القاهرة : مكتبة الثقافة الدينية.

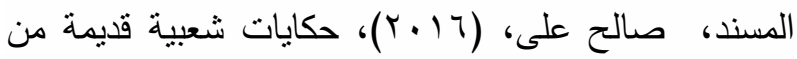
حارة الهنداوية بجدة، جدة، مكتبة كنوز المعرفة. المعب، زهرة سعد، (د ت) التجديف في عيون حالمة، جدة: دار العلم. المعبدي، مبارك محمد، (1994)، النشاط التجاري لميناء

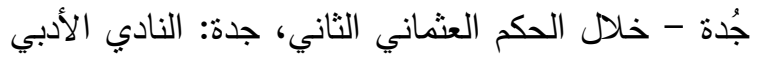
الثقافي.

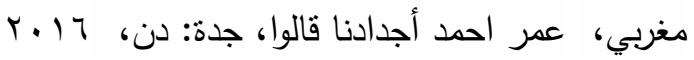

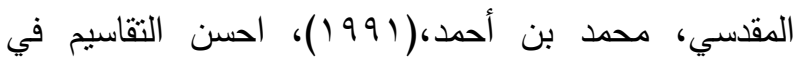
معرفة الأقاليم، بيروت: دار صادر .

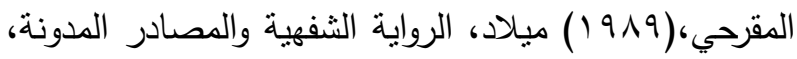

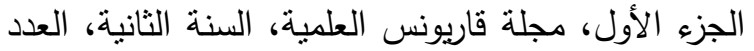

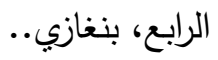

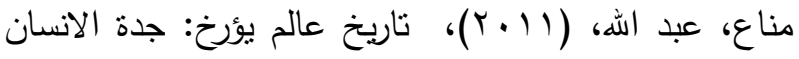
والمكان، جدة: دار المرسى للنشر والتوزيع.

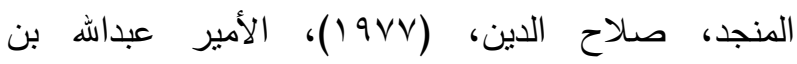

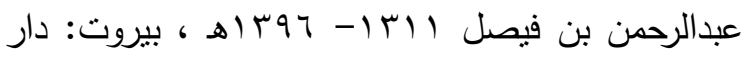

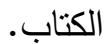

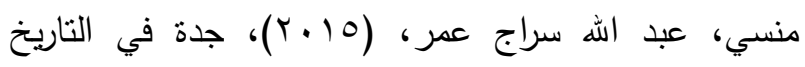

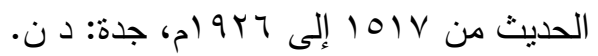

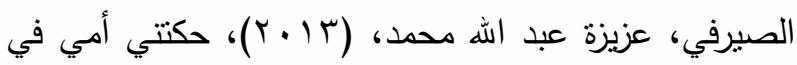
الناموسية حكاوي حلوة حجازية، جدة: دن.

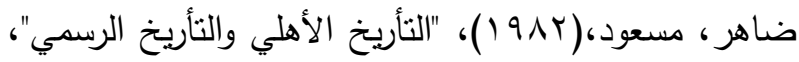

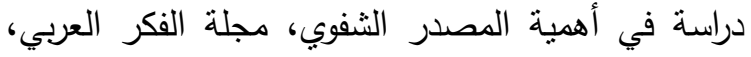
السنة ع ، العدد V rV مايو.

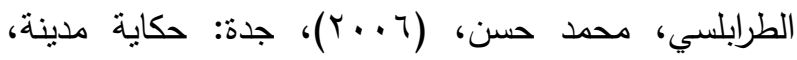

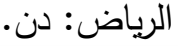
طرابلسي، محمد يوسف محمد، ( 17 (ب)، حدث في بندر

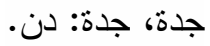
العامودي، هدى، و باقادر، أبو بكرة ، (199 (1)، الهجرة الريفية الحضرية :دراسة في تكيف المهاجرين إلى مدينة جدة، بيروت: دار المنتخب العربي.

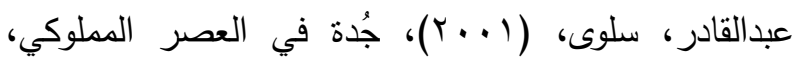
جدة: النادي الأدبي النقافي. العسكر، عبد الله بن ابراهيم، أهمية تدوين التراث الثفاهي

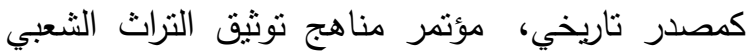

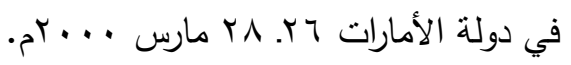

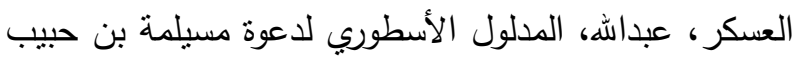

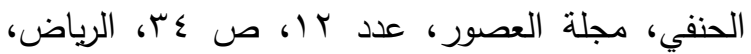
. 1994

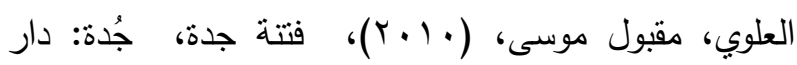
الكواكب. علي، قاسم هاثم حسين، (10 ب (Y)، جدة صفحات مشرقة من

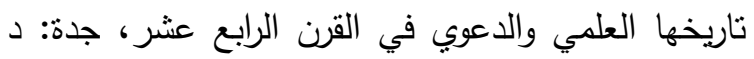

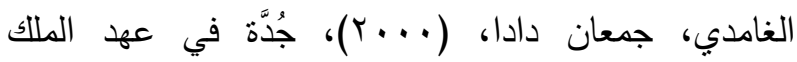
عبدالعزيز، القاهرة: دار الوادي الجديد.

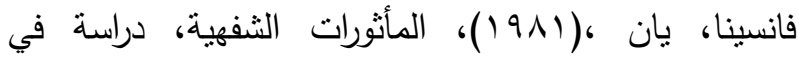
المنهجية التاريخية، ترجمة أحمد علي مرسي، القاهرة: دار الثقافة للطباعة والنشر •

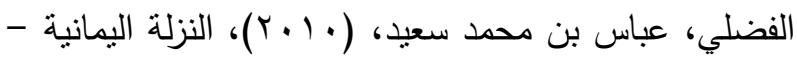

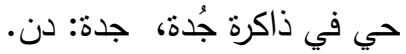

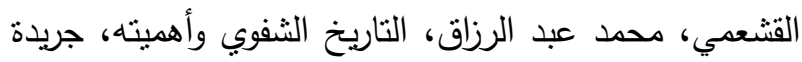

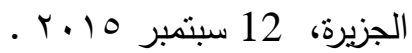




$$
\begin{aligned}
& \text { وليامسون، وليام ريتشارد، (ع . . r) رحلة إلى الخليج العربي، } \\
& \text { بيروت: الدار العربية. }
\end{aligned}
$$

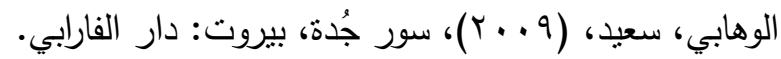

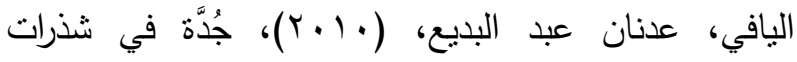

$$
\begin{aligned}
& \text { الغزاوي، جدة،: مطابع جريدة المدينة. }
\end{aligned}
$$

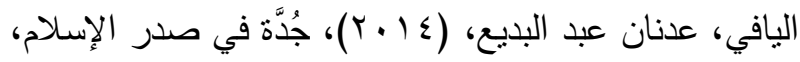

$$
\begin{aligned}
& \text { جدة: د ن. }
\end{aligned}
$$

\section{المصادر والمراجع الانجليزية}

Al-Khawaja Yanni (Yanni the Westerner): An Example of Muslim-Christian Tolerance in Jeddah during the 20th Century، Academic Journal of Interdisciplinary Studies، Vol 6. No 2. 2017.

Baack، Lawrence J. 2014)Undying curiosity. Carsten Niebuhr and the Royal Danish Expedition to Arabia (1761-1767). Stuttgart.

Badía y Leblich، D.F.J. Voyages d'Ali Bey el Abbassi en Afrique et en Asie pendant les Années 1803 ، 1804، 1805، 1806، et 1807، Paris: P. Didot l'Ainé، 1814.

Charles Didier (1985)Sojourn with the Grand Sharif of Makkah، Cambridge: Oleander Press.

Charlton، Thomas L. / Myers، Lois E. and Sharpless، Rebecca (2006). (ed.)‘ Handbook of Oral History ‘ Lanham (MD)، Altamira Press.

Edward Balfour( 1885) The cyclopedia of India and of eastern and southern Asia، London: B. Quaritch

Ingham، Bruce (1997) Arabian Diversions: Studies in the Dialects of Arabia. Ithaca Press.

Ingham، Bruce and bin، Atiyyah Qabilat al Dhafir Dirasa Lughawiyyah Muqarinah. Kuwait. (1995)

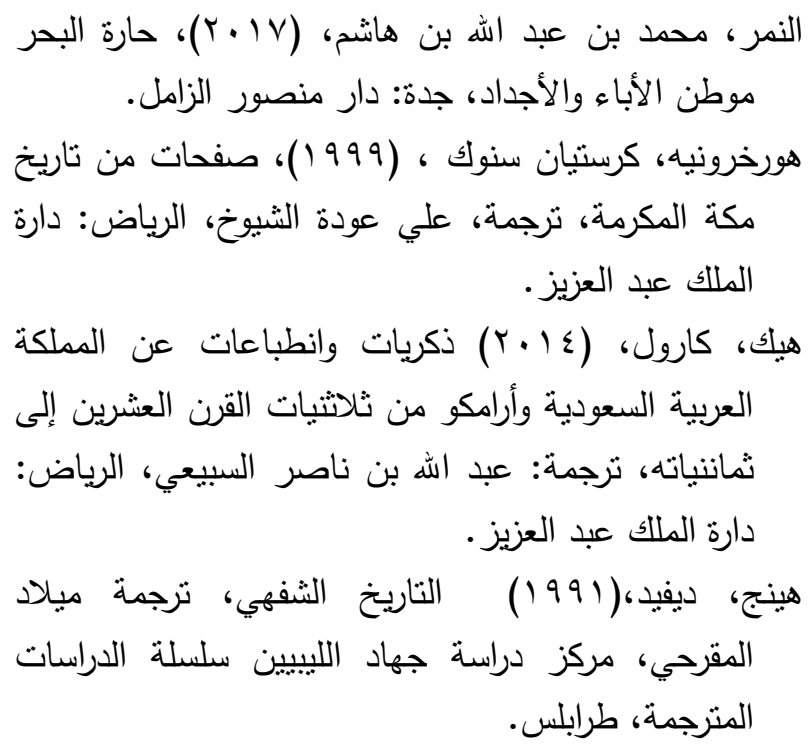

Ingham، Bruce Introduction to Simple Etiquette in Saudi Arabia and the Gulf States. Global Books Ltd. 1995. And Najdi Arabic: Central Arabian. John Benjamins، 1994. In addition 'Information structure in the Najdi dialects.' In: Owens، Jonathan and Elgibali، Alaa، (eds.)' Information Structure in Spoken Arabic. London; New York: Routledge، 2010. pp. 75-92. (Routledge Arabic Linguistics Series)

Lady Evelyn Cobbold، (2008) Pilgrimage to Mecca، Abu Dabai: Arabian.

Léon Roches،(1884) Trente-deux ans à travers l'Islam: (18321864)، Paris: Firmin-Didot.

Maurice Tamisier، (1840)Voyages en Arabie، séjour dans le Hedjaz ‘ campagnes d'Assis، Paris: Louis Desessart.

Robert Lowie، Oral Tradition and History، American Anthropologist، Vol. 17، No. 3 (Jul. - Sep.، 1915)‘ pp. 597599.

Sheftel، Anna and Zembrzycki، Stacey، (2013).Oral history off the record: toward an ethnography of practice 'New York، Palgrave Macmillan. 


\title{
Oral History of the City of Jeddah in the Nineteenth and Twentieth Century: An Analytical Documentary Study
}

\author{
Dr.. Hassna Al Ghamdi \\ Dr.. Tarek Al Ajal
}

\begin{abstract}
The oral history of cities and communities is one of the most important means for the historical writing of political, economic and cultural developments, as well as documenting the social transformations taking place in societies. The fact is that Jeddah is one of the most important cities in the Muslim World due to its geographical location and economic role, and that it is adjacent to the city of Mecca, the holiest city in Islam that all Muslims have a spiritual connection with. Paying attention to its oral history is one of the most important priorities for historians and intellectuals, especially with the apparent lack of historical writing on the city, and the existence of many gaps to be filled by further research and investigation. The study aims to collect and highlight all efforts made to cover the oral history of Jeddah, including previous studies on the city as well as presenting ideas for future studies. The study used an analytical survey methodology to cover all published works on the oral history of Jeddah. The researcher concluded a number assessments and recommendations that would be of a help to researchers and historians interested in documenting and chronicling the events and interactions of daily life and culture in the city of Jeddah.
\end{abstract}

